\title{
Chapter 9 \\ Review of the Mental Health and Well-being Benefits of Biodiversity
}

\author{
Melissa R. Marselle, Dörte Martens, Martin Dallimer, \\ and Katherine N. Irvine
}

\begin{abstract}
Little is known about the contribution that biodiversity has on mental health and well-being. To date, only one systematic review has investigated the health and well-being benefits from contact with biodiversity (Lovell et al. J Toxicol Environ Health B Crit Rev 17(1):1-20, 2014). The number of research studies investigating the health and well-being effects of biodiversity has increased since this publication. Here, we provide an update, focusing on the impact of biodiversity on mental health and well-being. Our objectives are to: (i) identify and describe the literature published after 2012; and (ii) synthesise all results from Lovell et al. (J Toxicol Environ Health B Crit Rev 17(1):1-20, 2014) and the more recently published literature to assess whether biodiversity influences mental health and wellbeing. Sixteen recently published studies met the inclusion criteria. The literature is varied with different study designs, measures of biodiversity, mental health and well-being. The synthesis of results was drawn from 24 studies: nine from Lovell et al. (J Toxicol Environ Health B Crit Rev 17(1):1-20, 2014) and 15 identified by this chapter. There is some evidence to suggest that biodiversity promotes better
\end{abstract}

\footnotetext{
M. R. Marselle ( $₫)$

Department of Ecosystem Services, Helmholtz Centre for Environmental Research - UFZ, Leipzig, Germany

German Centre for Integrative Biodiversity Research (iDiv) Halle-Jena-Leipzig,

Leipzig, Germany

e-mail: melissa.marselle@ufz.de

D. Martens

Eberswalde University for Sustainable Development, Eberswalde, Germany

e-mail: d.martens@hnee.de

M. Dallimer

Sustainability Research Institute, School of Earth and Environment, University of Leeds, Leeds, UK

e-mail: m.dallimer@leeds.ac.uk

K. N. Irvine

Social, Economic and Geographical Sciences Research Group, The James Hutton Institute, Aberdeen, Scotland, UK

e-mail: katherine.irvine@hutton.ac.uk
} 
mental health and well-being. However, more studies reported non-significant results. The evidence is not yet of the extent necessary to characterise the role of biodiversity in relation to mental health or well-being. Future interdisciplinary research directions are discussed.

Keywords Mental health · Mental well-being $\cdot$ Biodiversity $\cdot$ Species richness · Synthesis · Review

\section{Highlights}

- Research into the health and well-being effects of biodiversity has grown since Lovell et al. (2014).

- We update Lovell et al. (2014) and focus on the impact of biodiversity on mental health and well-being.

- 16 recently published studies on biodiversity and mental health and well-being were identified.

- Synthesis of results found some evidence that biodiversity promotes better mental health and well-being.

- Overall, more studies reported non-significant effects.

\subsection{Introduction}

Contact with natural environments facilitates diverse health and well-being benefits (Bowler et al. 2010; Frumkin 2001; Hartig et al. 2014; Irvine and Warber 2002; Keniger et al. 2013). However, in this body of research the natural environment is often "treated as uniform" (Dallimer et al. 2012, p. 48), as studies commonly compare broad urban and natural environment categories (e.g. Hartig et al. 2003; Korpela et al. 2016) or analyse the amount of, or proximity to, green space (e.g. Groenewegen et al. 2012; Triguero-Mas et al. 2015). Whilst a substantial amount of literature investigates the impact of nature or green space on health and well-being, little is known about the contribution that different qualities of the natural environment, such as biodiversity, have on mental health and well-being.

Systematic reviews of the mental health or well-being benefits from contact with nature do not include studies that assess the biodiversity of the natural environment (e.g. Bowler et al. 2010; Dadvand et al. 2015; Thompson Coon et al. 2011). This same body of literature on the mental health or well-being effects of nature is also present in systematic reviews of the health benefits of biodiversity (e.g. Horwitz and Kretsch 2015; Hough 2014; Whitmee et al. 2015), resulting in a closed loop of examined literature. To date, only one systematic review has explicitly investigated the health and well-being benefits from contact with biodiversity (Lovell et al. 2014). While the authors found some evidence for a positive benefit from exposure to biodiversity, overall, the synthesis of 15 quantitative studies showed no clear pattern of results for the effects of biodiversity on human health and well-being. 
Since the publication of Lovell et al. (2014), interest has grown in the potential contribution of biodiverse environments for health and well-being. Growth in this field is shown clearly by the increase in the number of related scientific publications. For example, a search in the Web of Science on just one term, 'biodiversity and health', yielded 0 hits for 1980-1989, 3 hits for 1990-1999, 2 hits for 2000 2009, 6 hits for 2010-2013, and 16 hits from 2014-2018. This coincides with increased interest from governments and international organisations on the mental health and well-being effects of biodiversity (Convention on Biological Diversity 2017a, b; EKLIPSE 2017; WBGU - German Advisory Council on Global Change 2016; World Health Organisation \& Secretariat of the Convention on Biological Diversity 2015). Given this research expansion and increased interest, in this chapter we update the literature reviewed by Lovell et al. (2014). In particular, we focus on the relationships between biodiversity and mental health and mental well-being, as such an analysis has yet to be conducted. Box 9.1 details these definitions.

The aim of this chapter is to identify, summarise and synthesise research on the impact of biodiversity on mental health and well-being. There are two objectives:

1. Describe the state and nature of the body of evidence, published since the review by Lovell et al. (2014), relating biodiversity to mental health and well-being;

2. Provide a synthesis of results from Lovell et al. (2014) and the more recently published literature to assess whether biodiversity influences mental health and well-being.

\section{Box 9.1: Definitions of Biodiversity, Health, Mental Health and Mental Well-being}

- Biodiversity is "the variability among living organisms from all sources including, inter alia, terrestrial, marine and other aquatic ecosystems and the ecological complexes of which they are part; this includes diversity within species, between species and of ecosystems" (United Nations Convention on Biological Diversity 1992, p. 3).

- Health is "a state of complete physical, mental and social well-being and not merely the absence of disease or infirmity" (World Health Organization 1946).

- Mental health "a state of well-being in which an individual realises his or her own abilities, can cope with the normal stresses of life, can work productively and is able to make a contribution to his or her community" (World Health Organization 2016).

- Mental well-being is "the psychological, cognitive and emotional quality of a person's life. This includes the thoughts and feelings that individuals have about the state of their life, and a person's experience of happiness" (Linton et al. 2016, p. 12). 


\subsection{Methods}

\subsubsection{Literature Review}

A systematic search strategy was used to identify published, peer-reviewed studies that specifically examined relationships between biodiversity and mental health or mental well-being outcomes. The literature search was conducted in October 2017, following a replicable procedure (Koricheva et al. 2013). Inclusion criteria (Box 9.2) was identical to those used by Lovell et al. (2014), except with a focus on literature published (i) between 2013 and September 2017, and (ii) in any language. Thus, we are building on, rather than replicating, the review by Lovell et al. (2014).

Literature was identified through structured searches of the Web of Science, which identified 189 articles (see the Appendix for the search terms). One reviewer $[\mathrm{MM}]$ initially screened titles and abstracts, with a second reviewer [DM] applying the inclusion criteria to articles that needed a second opinion. Nineteen articles were identified as eligible for full text review (see Fig. 9.1). Backward and forward reference searches (Cǒté et al. 2013) were conducted on these 19 articles. The resulting 1610 articles were first screened by year and title for eligibility, then abstracts were read. This method identified an additional four articles, all from forward citations. Backward and forward reference searches of these four articles resulted in an additional 242 references, which underwent a similar screening process. No new articles were identified. Twenty-three articles underwent full text screening (by MM and

\section{Box 9.2: Study Inclusion Criteria (Adapted from Lovell et al. 2014)}

1. Any peer-reviewed study, published between January 2013 and September 2017

2. Any recognised and reliable study design, with any population group, from any country and in any language

3. An explicit consideration of biodiversity, species richness and/or a setting protected because of its biodiversity, and

4. An explicit consideration of either a primary health-related outcome including any self-reported or objective measure of mental health or mental well-being, or a secondary health-related outcome including self-report or objective measures of physical activity or self-report social cohesion.

Exclusion criteria: Studies were excluded if they did not assess (i) biodiversity and (ii) mental health, mental well-being, physical activity and social cohesion related outcome measures. Studies assessing preferences, physiological outcomes, use/visitation, the amount of green space without specification of its biodiversity, or physical activity without identification of where it occurred were excluded. Studies not reporting primary research (e.g. review papers) were also excluded. 


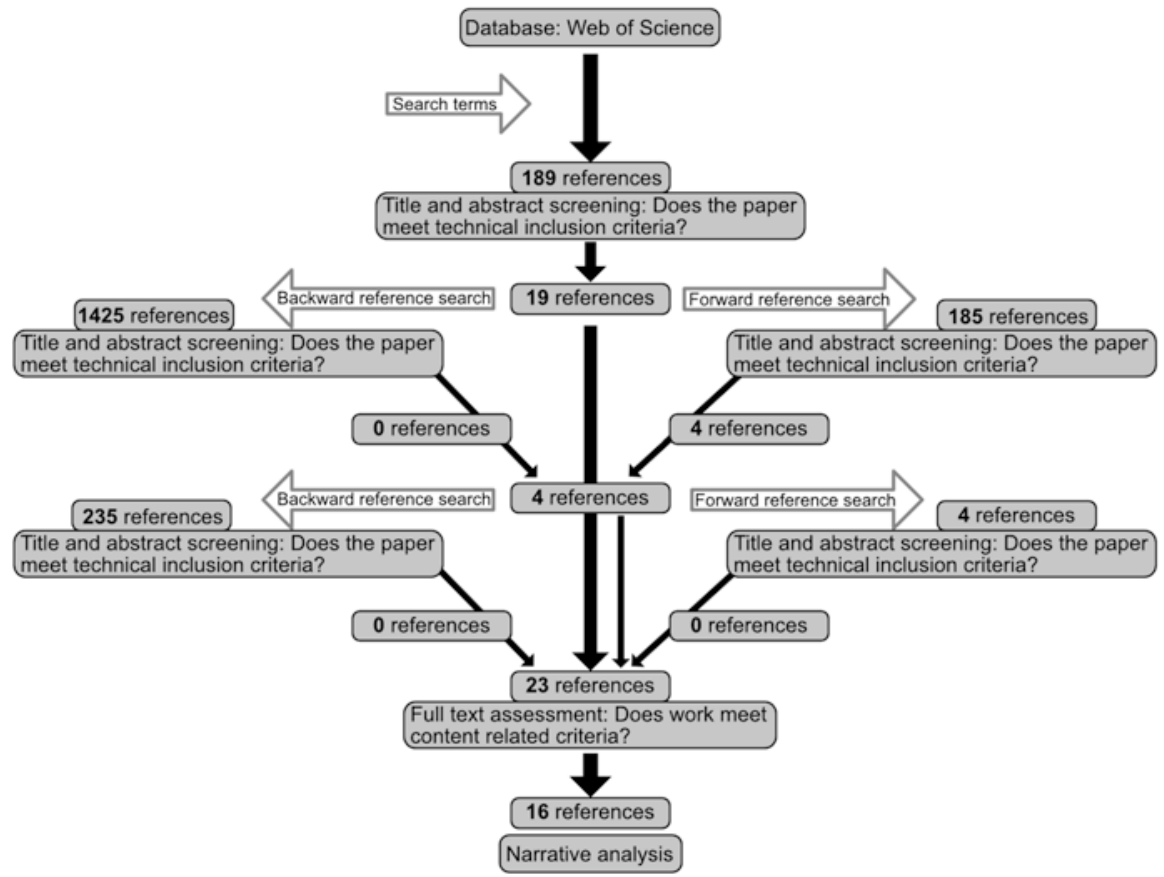

Fig. 9.1 Process of literature review and identified relevant articles

DM); seven were excluded primarily because they did not assess biodiversity, mental health, mental well-being, physical activity or social cohesion. In total, 16 articles were identified (see Table 9.1).

\subsubsection{Characteristics of the Recent Literature}

To describe the recently published literature on biodiversity and mental health and well-being, a standardised data extraction form was used to record relevant information from the 16 studies: country of origin, participants, theoretical position, biodiversity indicators, outcome measures, contact with biodiverse environment, moderators, mediators and results.

Biodiversity indicators were classified on the basis of biodiversity levels identified by Botzat et al. (2016) - namely, ecosystems/habitats (e.g. parks, forests); species communities (e.g. plants, birds, butterflies); or single species. Within the species community level, both species richness (e.g. the number of different bird species) and abundance of a specific taxonomic group irrespective of species (e.g. the number of all birds) were identified. Both variables have been shown to have differential effects (Hedblom et al. 2017). Abundance may be more important to mental health or mental well-being than the number of different species (Dallimer et al. 2012). 


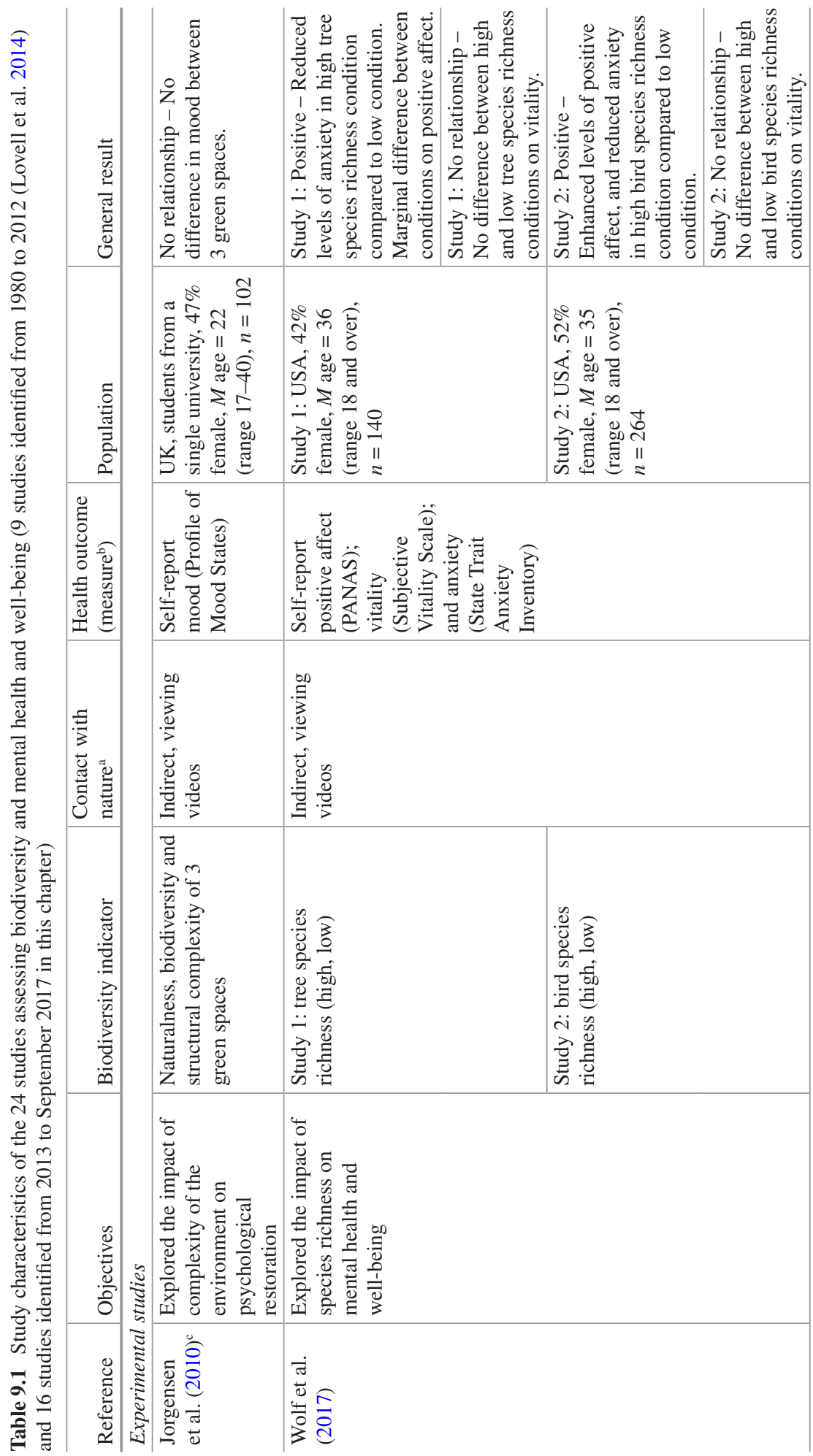




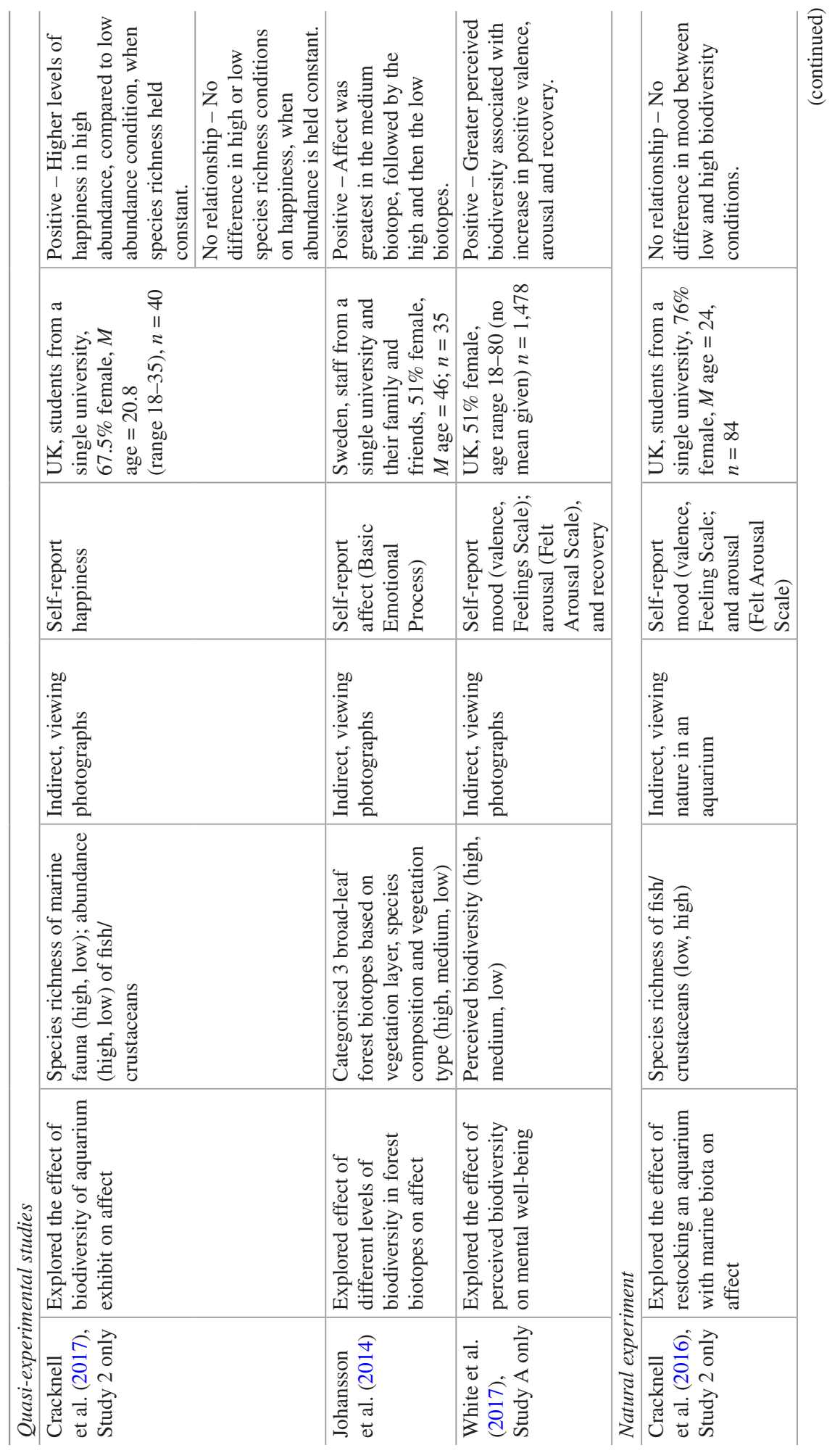




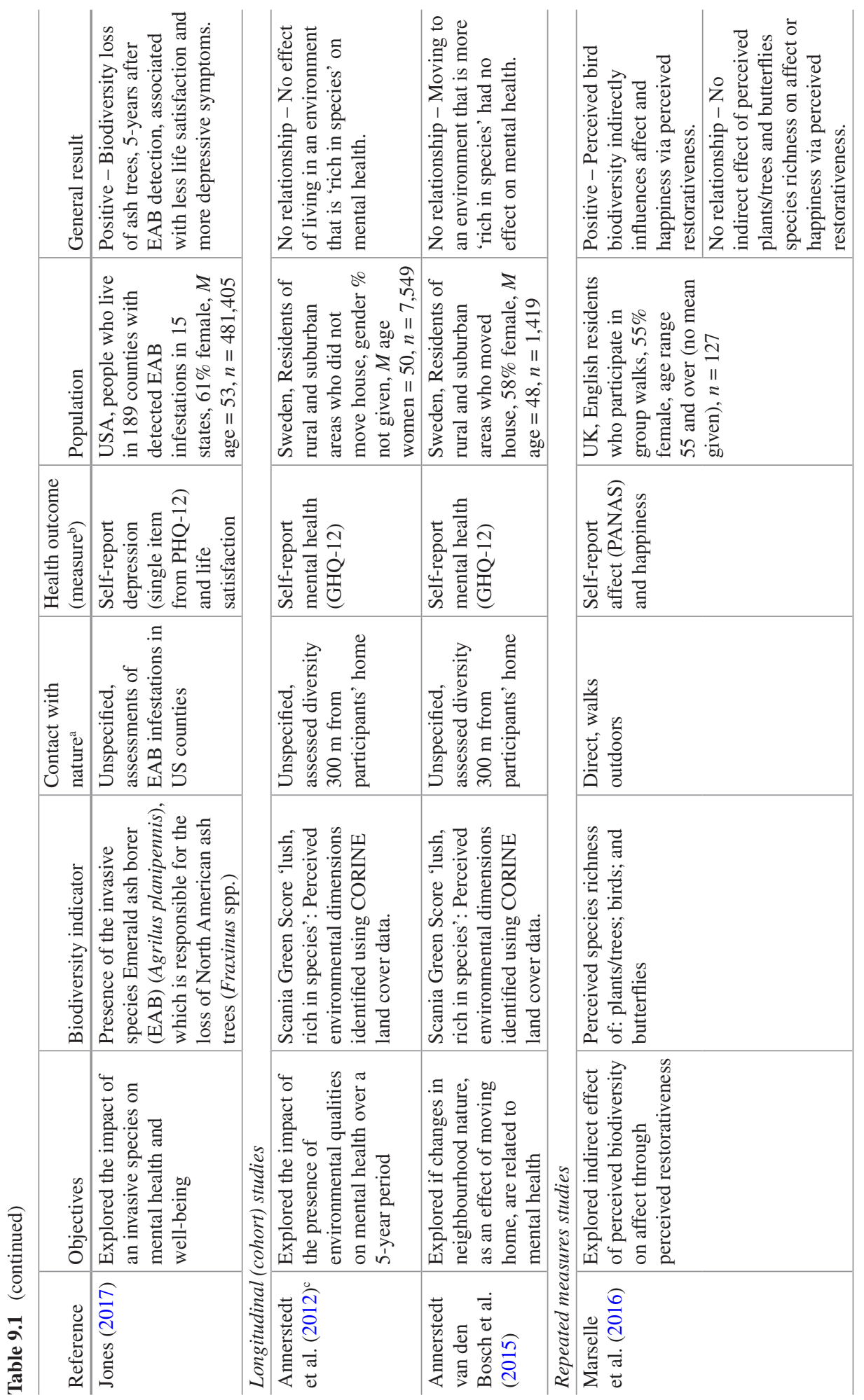




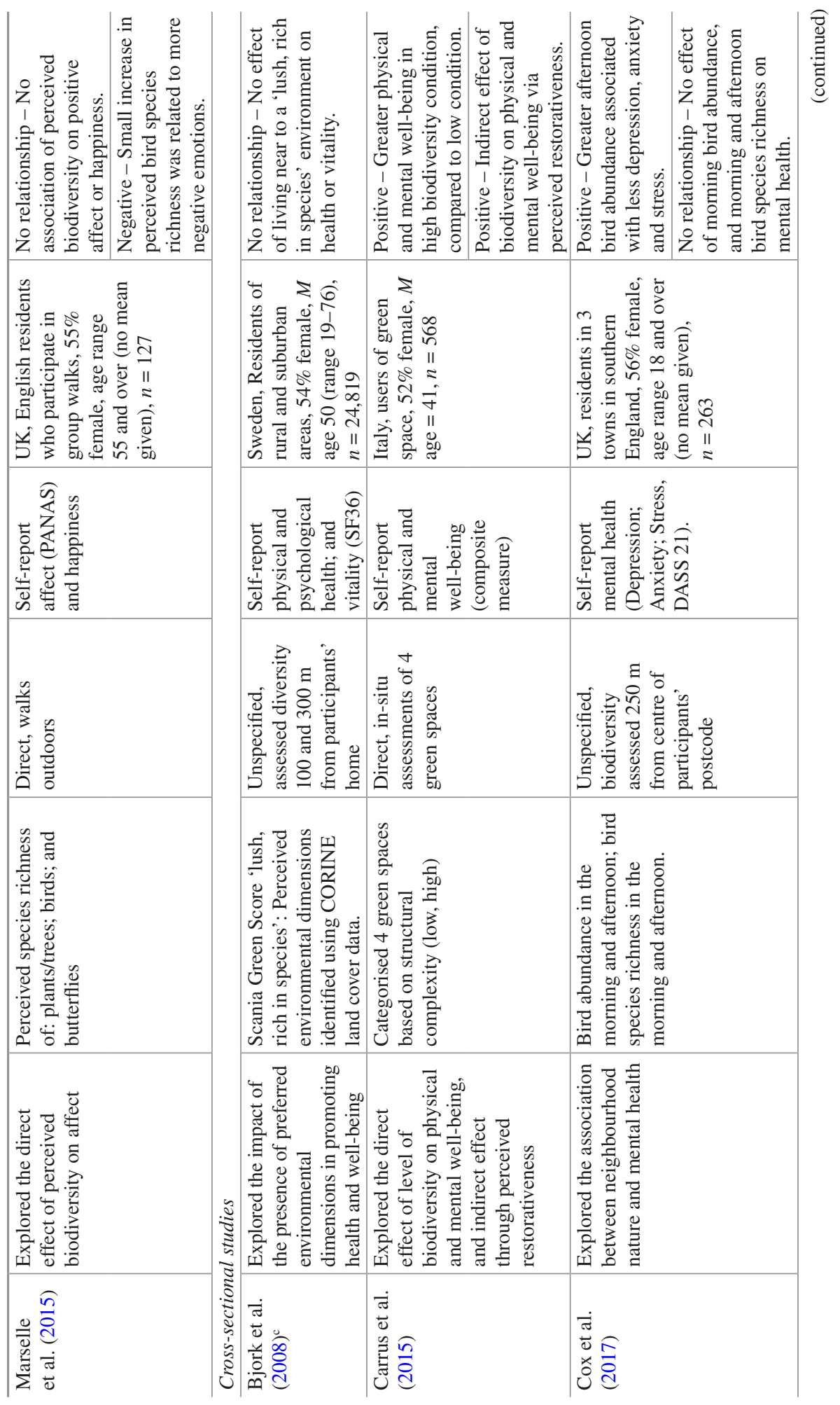




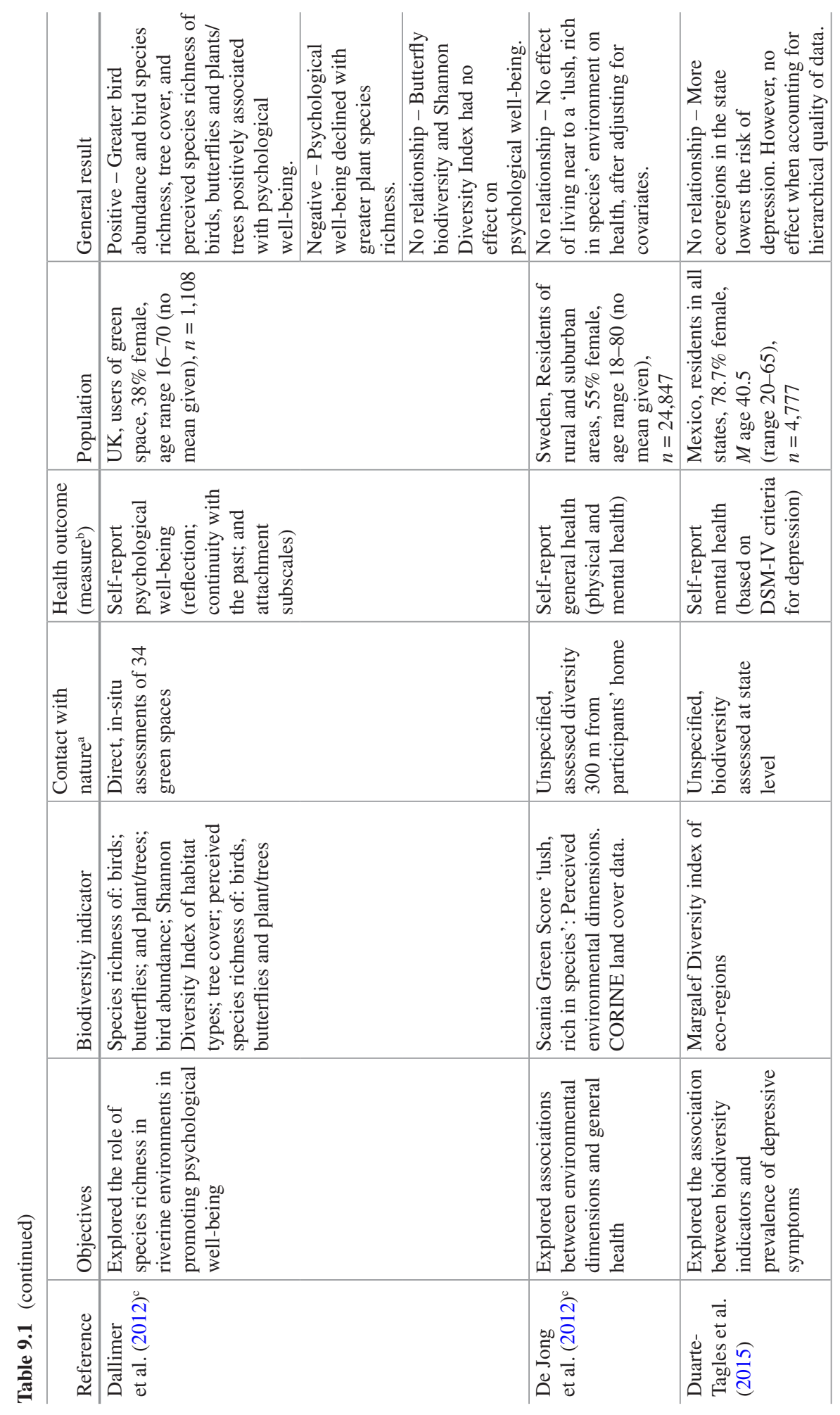




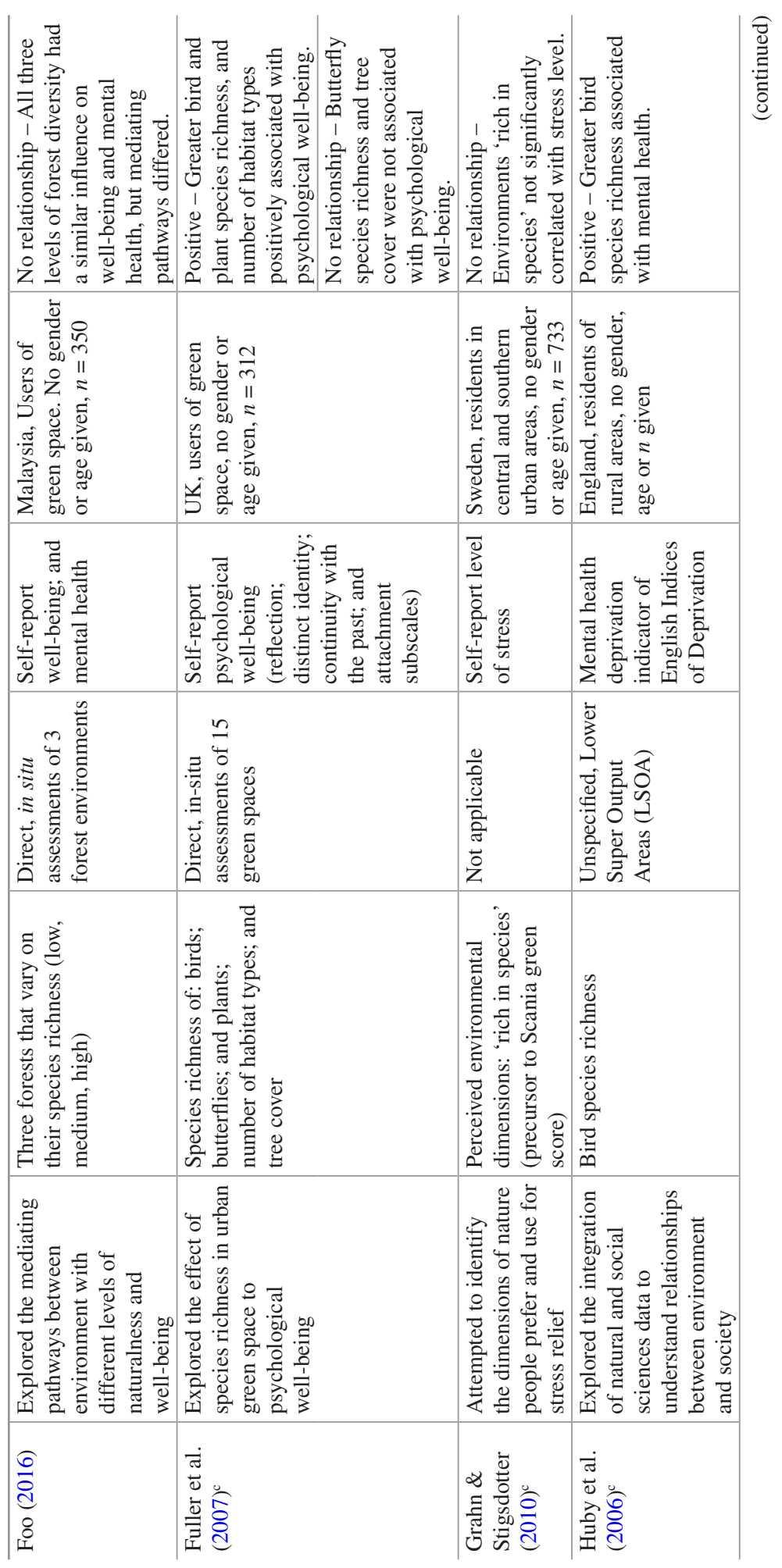




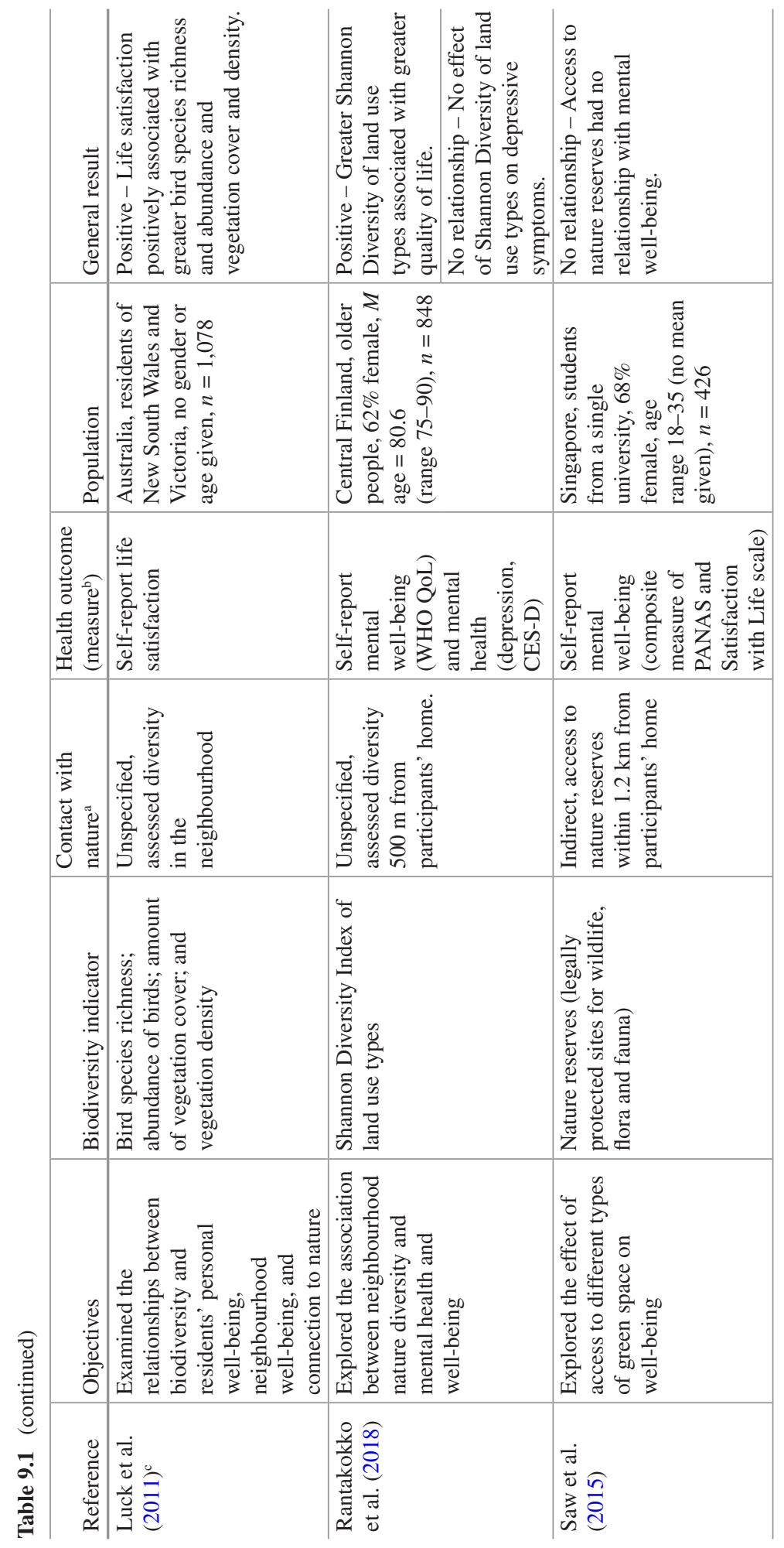




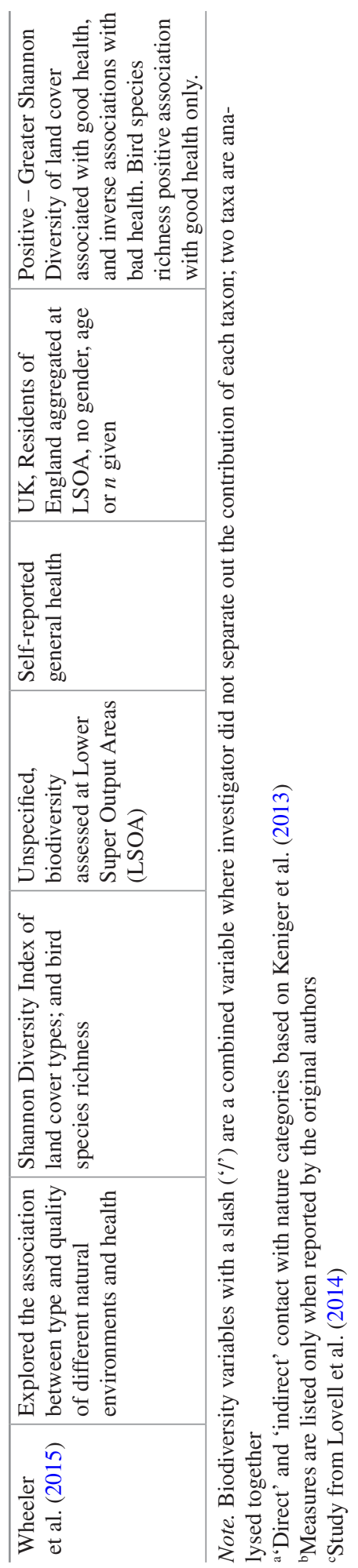


Contact with the biodiverse environment was coded as either indirect or direct following Keniger et al. (2013). Indirect contact "does not require a person to be physically present in nature" (Keniger et al. 2013, p. 916) and can include viewing nature through a window, and looking at photographs, paintings or motion pictures of nature. Direct contact with nature stipulates that nature, or natural elements, are physically present in the same space as the individual (Keniger et al. 2013). ${ }^{1}$ Examples of direct contact include indoor plants, using urban green spaces for education purposes, reading or having a picnic in the park, doing sports or exercise in a natural setting, gardening and camping.

Moderating variables were categorised as either personal (e.g. age, gender, socioeconomic status) or contextual (e.g. urbanicity, safety) (Hartig et al. 2014; Markevych et al. 2017). Mediators were classified as 'reducing harm', 'restoring capacities' or 'building capacities' according to Markevych et al. (2017). 'Reducing harm' considers the role of the natural environment to reduce exposure to environmental stressors like heat or noise pollution. 'Restoring capacities' mediators support renewal of adapted resources that have become depleted through everyday demands, such as attention restoration and stress recovery. 'Building capacities' mediators highlight the role of green spaces in strengthening an individual's capacity to acquire new adaptive resources like fostering physical activity and social cohesion.

\subsubsection{Synthesis of Results}

To provide a synthesis of results assessing the influence of biodiversity on mental health and well-being, a combined set of 24 studies, drawn from Lovell et al. (2014) and from our updated review, was utilised. Nine quantitative studies identified in Lovell et al. (2014) that assessed biodiversity and mental health and well-being relationships were included (Table 9.1). Consequently, 4 studies from Lovell et al. (2014) with physical health as the outcome were excluded (Huynen et al. 2004; Poudyal et al. 2009; Sieswerda et al. 2001; Tilt et al. 2007). Also excluded were 4 studies that, according to Lovell et al. (2014), did not directly assess biodiversity but were included in their analysis nevertheless (Barton et al. 2009; Curtin 2009; Lemieux et al. 2012; Pereira et al. 2005). In this sense our synthesis of results is more critical than Lovell et al.'s (2014) by including only those studies that consider the biodiversity of the environment in some way. Fifteen of the 16 articles identified in our updated search were included in the synthesis of results. Foo (2016) was excluded from the synthesis of results because it analysed the associations between use of the environment, individual differences in environmental experience, and perceived physical activity, well-being and mental health given a certain level of actual biodiversity instead of an investigation of the influence of biodiversity levels on mental health and well-being.

\footnotetext{
${ }^{1}$ This is a combination of Keniger et al. (2013) 'incidental' and 'intentional' interaction types as both describe being in the presence of nature.
} 
Due to the heterogeneity of the selected articles in terms of research design, measures and participants, data were analysed using narrative synthesis (Popay et al. 2006). The purpose of narrative synthesis is to identify the factors that explain the differences in results in the body of literature (Popay et al. 2006). Patterns of results across all 24 studies were identified according to study design, measures of biodiversity and mental health or well-being. Vote counting (Popay et al. 2006) was used to describe the frequency of significant and non-significant results across the 24 quantitative studies. This analytical approach has been used previously (Lovell et al. 2014). While we acknowledge that vote counting has known deficiencies (e.g. giving equal weight to studies with different research designs, samples and effect sizes), it is a useful as a preliminary interpretation of results across studies (Popay et al. 2006). Our findings should thus be interpreted with caution.

\subsection{Results}

\subsubsection{Characteristics of the Recent Literature, Published Since Lovell et al.'s (2014) Review, Relating Biodiversity to Mental Health and Well-being}

The following describes the recent literature $(n=16)$, published since 2012, on biodiversity and mental health and well-being. See Lovell et al. (2014) for description of the body of evidence up to 2012.

All 16 studies examined, wholly or in part, the relationships between biodiversity and one or more mental health or well-being outcomes (see Table 9.1). Eleven studies were based in Western Europe, three in North America and two in Asia. Two studies were from emerging economies of Malaysia and Mexico. Six different study designs were used to examine the relationship between biodiversity and mental health and well-being (Fig. 9.2).

\subsubsection{Spatial Scale}

The spatial scale at which the relationships were examined ranged from the national (Duarte-Tagles et al. 2015; Wheeler et al. 2015) to the local (Carrus et al. 2015; Foo 2016; Marselle et al. 2015, 2016). Specifically, scales considered whole countries (England (Wheeler et al. 2015) and Mexico (Duarte-Tagles et al. 2015)), geographical regions within countries (England (Cox et al. 2017), Finland (Rantakokko et al. 2018), Sweden (Annerstedt van den Bosch et al. 2015), the USA (Jones 2017)) and specific places such as forests in the Klang Valley region of Malaysia (Foo 2016), protected nature reserves in Singapore (Saw et al. 2015) and green spaces in Italy (Carrus et al. 2015). 


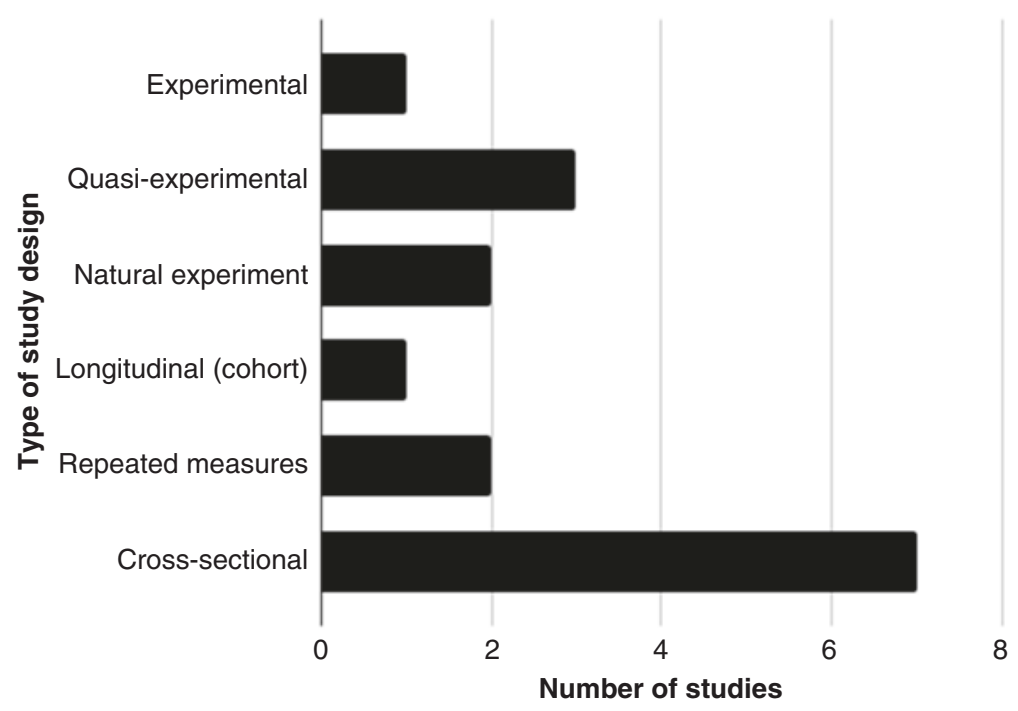

Fig. 9.2 Type of study design used to examine biodiversity and mental health and well-being relationships across the 16 studies published after 2012

\subsubsection{Participants}

The number of participants varied considerably among the recently published studies: ranging from 35 (Johansson et al. 2014) through to the millions (with the use of data from the national census, Wheeler et al. 2015). Participant type also differed, including university students (Cracknell et al. 2016, 2017; Saw et al. 2015) and staff (Johansson et al. 2014), adults participating over the internet (White et al. 2017; Wolf et al. 2017), group walkers over the age of 55 (Marselle et al. 2015; Marselle et al. 2016), park users (Carrus et al. 2015), visitors to forests (Foo 2016), and residents of specific countries or regions as previously detailed (Annerstedt van den Bosch 2015; Cox et al. 2017; Duarte-Tagles et al. 2015; Jones 2017; Rantakokko et al. 2018; Wheeler et al. 2015).

\subsubsection{Theoretical Position}

Where articulated, the theoretical underpinnings largely reflected the dominant understandings of environment-health linkages (for further discussion on biodiversity and health theories, see Marselle Chap. 7, this volume). Specifically, 9 studies (Annerstedt van den Bosch, et al. 2015; Cox et al. 2017; Cracknell et al. 2016, 2017; Foo 2016; Marselle et al. 2015, 2016; Saw et al. 2015; White et al. 2017) used the Attention Restoration Theory (Kaplan and Kaplan 1989; Kaplan 1995) and the Stress Reduction Theory (Ulrich 1983; Ulrich et al. 1991) to explain the effects of biodiversity on mental health and/or well-being. Additionally, the Biophilia hypothesis (Kellert and Wilson 1993) was also mentioned (Annerstedt van den Bosch et al. 
2015; Carrus et al. 2015; Saw et al. 2015; Wolf et al. 2017), as was appraisal theory (Johansson et al. 2014). Four studies (Duarte-Tagles et al. 2015; Jones 2017; Rantakokko et al. 2018; Wheeler et al. 2015) did not articulate a theory for why or how biodiversity may be related to better health and well-being.

\subsubsection{Biodiversity Assessment}

There was considerable variation across the 16 studies on the organisational level at which biodiversity was studied, the data collection method used, and the type of environment/organism investigated (see Table 9.2). Seven studies assessed biodiversity at the ecosystem or habitat level. Measurement across these studies included use of secondary, geographically-referenced data to determine land cover and land use diversity using the Shannon Diversity Index (Rantakokko et al. 2018; Wheeler et al. 2015), eco-region diversity using the Margalef Diversity Index (Duarte-Tagles et al. 2015) and access to protected areas (Saw et al. 2015). Investigator categorisation of ecosystem/habitat biodiversity was used to classify environments into low, medium and high biodiversity biotopes (Johansson et al. 2014) or low vs. high biodiverse green spaces (Carrus et al. 2015). Participants' perception of habitats/ecosystem was used in one study; the Scania Green Score uses interpreted satellite imagery-derived land use data (i.e. mixed forest and marshes, beaches, sand plains and bare rock, biotopes and national parks) to map perceived biodiversity ('lush, rich in species') of an environment (Annerstedt van den Bosch et al. 2015). At the species community level, 6 studies assessed biodiversity in terms of species richness for various taxa (i.e. birds, butterflies, plants, trees, fish/crustaceans). Species richness was measured using standard ecological field survey techniques (Cox et al. 2017; Cracknell et al. 2016), secondary data (Wheeler et al. 2015) or investigator categorisation of species richness (e.g. low vs. high based on assessment of content in images or videos (Cracknell et al. 2017; Wolf et al. 2017)). Participants' perception of species richness was employed in 3 studies (Marselle et al. 2015, 2016; White et al. 2017). At the species community level, abundance of a specific taxonomic group (i.e. birds, fish/crustaceans) was also assessed in 2 studies using standard ecological survey techniques (Cox et al. 2017), and investigator categorisation of stimuli (i.e. low vs. high abundance; Cracknell et al. 2017). At the single species level, Jones (2017) investigated biodiversity loss and ecosystem health through the loss of North American ash trees (Fraxinus spp.) following the presence of the invasive species emerald ash borer (EAB) (Agrilus planipennis). This was assessed using secondary data.

\subsubsection{Mental Health and Well-being Assessment}

There was considerable variation in the outcomes considered and the measures used among the studies (Fig. 9.3). Mental health was assessed in 7 studies (Annerstedt van den Bosch et al. 2015; Cox et al. 2017; Duarte-Tagles et al. 2015; Foo 2016; 


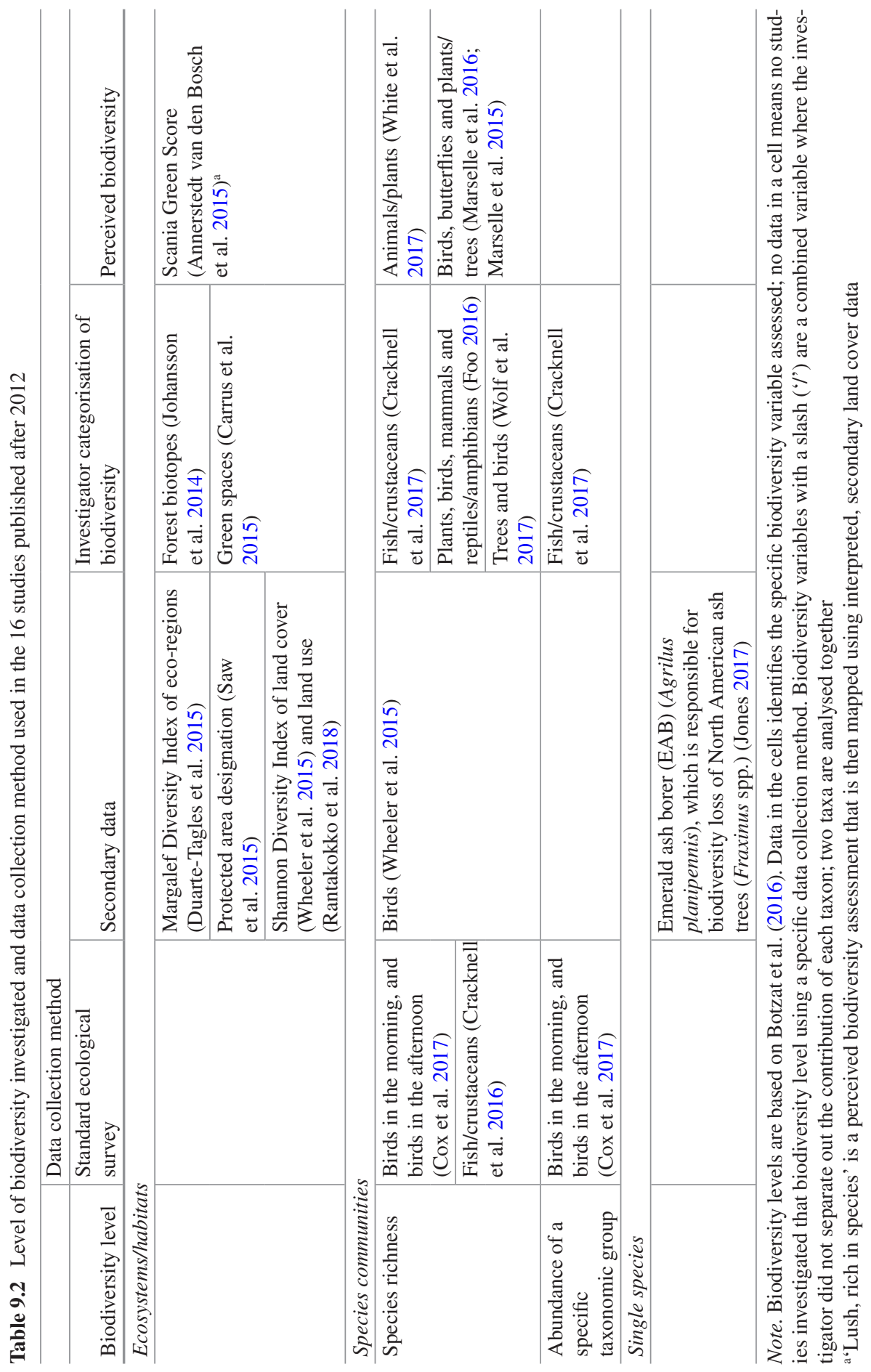


Jones 2017; Rantakokko et al. 2018; Wolf et al. 2017). The majority of these assessed depression (Cox et al. 2017; Duarte-Tagles et al. 2015; Jones 2017; Rantakokko et al. 2018) using self-report standardised measures such as the DASS (Cox et al. 2017), CES-D (Rantakokko et al. 2018) and PHQ-12 (Jones 2017). Anxiety was assessed also through the use of standardised self-report measures: DASS (Cox et al. 2017) and the STAI (Wolf et al. 2017). The DASS was additionally used to assess perceived stress (Cox et al. 2017). General mental health was assessed by Foo (2016) who utilised scales specifically developed for the study.

Mental well-being was examined in 13 studies (Carrus et al. 2015; Cracknell et al. 2016, 2017; Foo 2016; Johansson et al. 2014; Jones 2017; Marselle et al. 2015, 2016; Rantakokko et al. 2018; Saw et al. 2015; Wheeler et al. 2015; White et al. 2017; Wolf et al. 2017). The majority assessed emotions (Cracknell et al. 2016, 2017; Johansson et al. 2014; Jones 2017; Marselle et al. 2015, 2016; White et al. 2017; Wolf et al. 2017) using standardised self-report measures such as the PANAS (Marselle et al. 2015, 2016; Wolf et al. 2017), the Feeling Scale and Felt Arousal Scale (Cracknell et al. 2016; White et al. 2017), and the Basic Emotional Process 12 (Johansson et al. 2014). Quality of life was assessed with the WHO QoL (Rantakokko et al. 2018). Four studies measured general well-being: 3 studies (Carrus et al. 2015; Foo 2016; Wheeler et al. 2015) did not separate physical from mental well-being, and 1 study (Saw et al. 2015) did not separate mood (a short-term, affective aspect of well-being) from life satisfaction (a long-term, cognitive aspect of well-being, Diener et al. 1985).

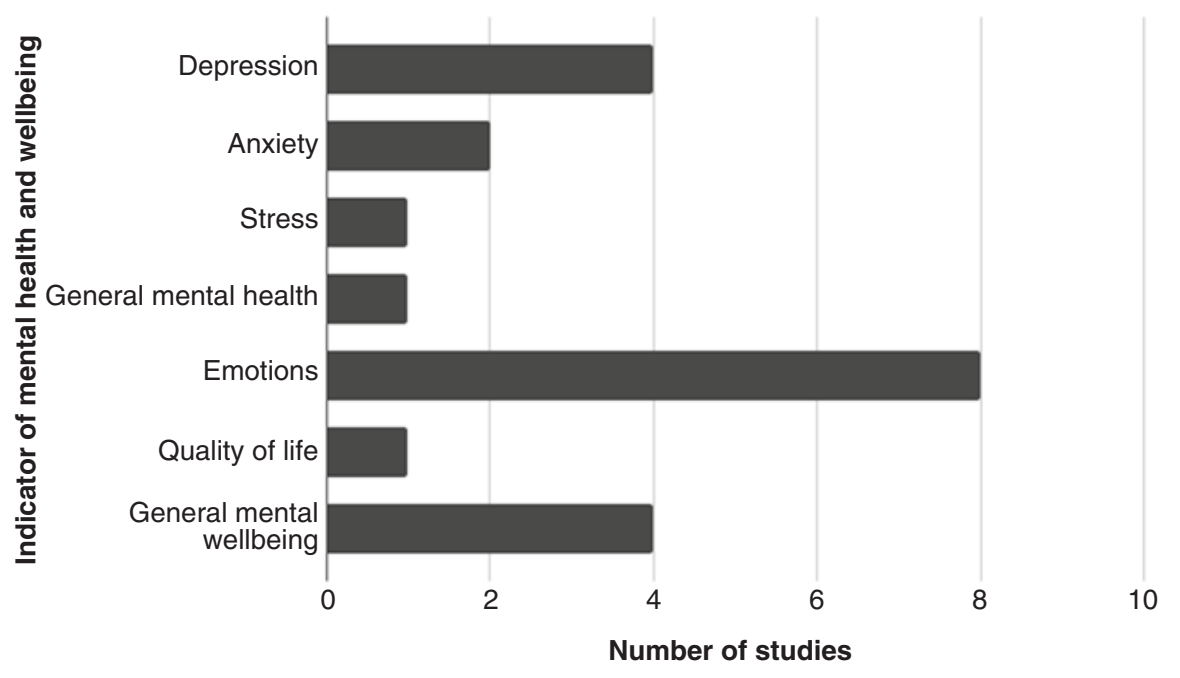

Fig. 9.3 Number of mental health and mental well-being variables used across the 16 studies published after 2012 . The sum may exceed $100 \%$ because some studies address more than one mental health or well-being variable 


\subsubsection{Type of Contact with the Biodiverse Environment}

Table 9.3 details the type of contact by biodiversity level. In general, authors hypothesised that direct or indirect contact with high biodiverse environments would have a positive effect on mental health and well-being. However, the majority of studies investigated the amount of biodiversity near to the home without specifying the type of contact (Annerstedt van den Bosch et al. 2015; Cox et al. 2017; Duarte-Tagles et al. 2015; Jones 2017; Rantakokko et al. 2018; Saw et al. 2015; Wheeler et al. 2015). Five studies, all experimental, considered indirect contact with biodiversity (Cracknell et al. 2016, 2017; Johansson et al. 2014; White et al. 2017; Wolf et al. 2017). In these studies, participants experienced biodiversity indirectly by viewing photographs (Cracknell et al. 2017; Johansson et al. 2014; White et al. 2017), videos (Wolf et al. 2017) or an aquarium exhibit (Cracknell et al. 2016). Four studies considered direct contact with biodiversity by assessing users who were in specific environments (Carrus et al. 2015; Foo 2016; Marselle et al. 2015, 2016). The impacts of changes in biodiversity on mental health and well-being were investigated in 2 studies. Annerstedt van den Bosch et al. (2015) assessed the relationship between mental health and moving to a neighbourhood that is perceived to be 'lush, rich in species'. Jones (2017) examined the mental health and well-being impact of biodiversity loss of North American ash trees due to the invasive species EAB. None of the studies investigated dose-response relationships of the effect of biodiversity on mental health or well-being.

\subsubsection{Moderation Analyses}

Moderation analyses were conducted in 4 studies (Carrus et al. 2015; Jones 2017; Wheeler et al. 2015; White et al. 2017). These were categorised as either personal (e.g. gender, age, socio-economic status) or contextual (e.g. urbanicity), based on previous research (Hartig et al. 2014; Markevych et al. 2017). Gender was found to moderate the influence of perceived biodiversity on positive affect and recovery; men reported greater positive affect and recovery from high (perceived) species rich environments (White et al. 2017). Age moderated the effect of perceived species richness on arousal (White et al. 2017), and biodiversity loss on life satisfaction (Jones 2017). People less than 35 years old reported more arousal from a perceived species rich environment, than those aged 35 and over (White et al. 2017). Whilst all age groups reported a reduction in life satisfaction from living in EAB infected areas, the largest (and only statistically significant) impact was for young adults aged 18-24 years old (Jones 2017). Socio-economic status was found to moderate the effect of biodiversity on health; the associations of Shannon Diversity of land cover types and bird species richness on health were the strongest for individuals who lived in the most socio-economically deprived neighbourhoods (Wheeler et al. 2015). Other personal variables such as being a member of an environmental organisation (White et al. 2017) had no moderating effect. The biodiversity-health relationship was also moderated by urbanicity. In Wheeler et al.'s (2015) study, Shannon Diversity of land cover types had the strongest association with good health for 
Table 9.3 Level of biodiversity investigated by the type of contact with biodiversity investigated in the 16 studies published after 2012

\begin{tabular}{|c|c|c|c|}
\hline \multirow{2}{*}{$\begin{array}{l}\text { Biodiversity } \\
\text { levels }\end{array}$} & \multicolumn{3}{|c|}{ Type of contact with biodiversity } \\
\hline & Direct & Indirect & Unspecified \\
\hline \multicolumn{4}{|c|}{ Ecosystem/habitats } \\
\hline & \multirow[t]{4}{*}{$\begin{array}{l}\text { Green spaces (Carrus } \\
\text { et al. 2015) }\end{array}$} & \multirow{4}{*}{$\begin{array}{l}\text { Forest biotopes } \\
\text { (Johansson et al. } \\
\text { 2014) }\end{array}$} & $\begin{array}{l}\text { Margalef Diversity Index } \\
\text { (Duarte-Tagles et al. 2015) }\end{array}$ \\
\hline & & & $\begin{array}{l}\text { Protected area designation (Saw } \\
\text { et al. 2015) }\end{array}$ \\
\hline & & & $\begin{array}{l}\text { Scania Green Score (Annerstedt } \\
\text { van den Bosch et al. 2015) }\end{array}$ \\
\hline & & & $\begin{array}{l}\text { Shannon Diversity Index (Wheeler } \\
\text { et al. 2015; Rantakokko et al. } \\
\text { 2018) }\end{array}$ \\
\hline \multicolumn{4}{|c|}{ Species communities } \\
\hline \multirow[t]{3}{*}{ Species richness } & $\begin{array}{l}\text { Birds, plants/trees, } \\
\text { and butterflies } \\
\text { (Marselle et al. 2016; } \\
\text { Marselle et al. 2015) }\end{array}$ & $\begin{array}{l}\text { Animals/plants } \\
\text { (White et al. } \\
\text { 2017) }\end{array}$ & $\begin{array}{l}\text { Birds in the morning, and birds in } \\
\text { the afternoon (Cox et al. 2017) }\end{array}$ \\
\hline & \multirow{2}{*}{$\begin{array}{l}\text { Plants, birds, } \\
\text { mammals and } \\
\text { reptiles/amphibians } \\
\text { (Foo 2016) }\end{array}$} & $\begin{array}{l}\text { Fish/crustaceans } \\
\text { (Cracknell et al. } \\
\text { 2016, 2017) }\end{array}$ & \multirow[t]{2}{*}{ Birds (Wheeler et al. 2015) } \\
\hline & & $\begin{array}{l}\text { Trees and birds } \\
\text { (Wolf et al. 2017) }\end{array}$ & \\
\hline $\begin{array}{l}\text { Abundance a } \\
\text { specific } \\
\text { taxonomic } \\
\text { group }\end{array}$ & & $\begin{array}{l}\text { Fish/crustaceans } \\
\text { (Cracknell et al. } \\
\text { 2017) }\end{array}$ & $\begin{array}{l}\text { Birds in the morning, and birds in } \\
\text { the afternoon (Cox et al. 2017) }\end{array}$ \\
\hline \multicolumn{4}{|l|}{ Single species } \\
\hline & & & $\begin{array}{l}\text { Emerald ash borer (Agrilus } \\
\text { planipennis), which is responsible } \\
\text { for biodiversity loss of North } \\
\text { American ash trees (Fraxinus } \\
\text { spp.) (Jones 2017) }\end{array}$ \\
\hline Total & 4 & 5 & 7 \\
\hline
\end{tabular}

Note. 'Direct' and 'indirect' contact with nature categories based on Keniger et al. (2013). Biodiversity levels are based on Botzat et al. (2016). Data in the cells identifies the specific biodiversity variable assessed in each study; no data in a cell means no studies investigated that biodiversity level and type of contact with the biodiverse environment. Biodiversity variables with a slash ('/) are a combined variable where the investigator did not separate out the contribution of each taxon; two taxa are analysed together

individuals who lived in rural areas, whilst, conversely, bird species richness had the strongest positive effect on health for those who lived in urban areas. Carrus et al. (2015) found a high level of biodiversity was more strongly associated with wellbeing in urban green spaces than in peri-urban areas suggesting that higher biodiversity is more important in urban areas for well-being. Other contextual variables, such as living near to the coast (White et al. 2017), had no moderating effect. 


\subsubsection{Mediation Analyses}

Mediators were explored in 3 studies (Carrus et al. 2015; Foo 2016; Marselle et al. 2016). Investigated mediators fell within two of the three domains mentioned by Markevych et al. (2017): 'restoring capacities' (perceived restorativeness (Carrus et al. 2015; Foo 2016; Marselle et al. 2016)) and 'building capacities' (physical activity and social interaction (Foo 2016)). 'Reducing harm' mediators were not investigated in these studies. Perceived restorativeness was found to mediate the relationship between biodiversity of green space and general well-being (Carrus et al. 2015), and between perceived bird species richness and positive affect, happiness and negative affect (Marselle et al. 2016). Perceived bird species richness also had an indirect effect on positive affect and happiness via the restorative components of being away, fascination and compatibility, and an indirect effect on negative affect via compatibility (Marselle et al. 2016). Foo (2016) conducted path analyses to determine how spending time in forest environments with different levels of biodiversity influenced mental health and general well-being. Multiple mediating pathways were found; time spent in a forest environment with intermediate or high biodiversity engendered a sense of being away, which was positively associated with a change in mood, which then was related to mental health. In only the high biodiverse forest was mental health related to general well-being. In the intermediate biodiverse forest, physical activity mediated the relationships between being away and mental health and general well-being. Social interaction did not mediate the effect of a forest environment on either outcome.

\subsubsection{Synthesis of the Results from the Combined Published Literature on Biodiversity and Mental Health and Well- being Relationships}

A combined set of 24 studies were included in the synthesis of results pertaining to the influence of biodiversity and mental health and well-being: 15 of the 16 recently published studies identified through our search process and nine of the 16 studies identified in Lovell et al. (2014). Fourteen of these 24 studies reported one or more positive associations between biodiversity and mental health or well-being outcomes (Carrus et al. 2015; Cox et al. 2017; Cracknell et al. 2017; Dallimer et al. 2012; Foo 2016; Fuller et al. 2007; Huby et al. 2006; Johansson et al. 2014; Jones 2017; Luck et al. 2011; Marselle et al. 2016; Rantakokko et al. 2018; Wheeler et al. 2015; White et al. 2017; Wolf et al. 2017) (see Table 9.4). Seventeen of the 24 studies reported one or more results with no significant relationship (Annerstedt van den Bosch et al. 2015; Annerstedt et al. 2012; Björk et al. 2008; Cox et al. 2017; Cracknell et al. 2016, 2017; Dallimer et al. 2012; de Jong et al. 2012; Duarte-Tagles et al. 2015; Fuller et al. 2007; Grahn and Stigsdotter 2010; Jorgensen et al. 2010; Marselle et al. 2015, 2016; Rantakokko et al. 2018; Saw et al. 2015; Wolf et al. 2017). Two studies reported one or more negative associations between biodiversity and mental health or well-being outcomes (Dallimer et al. 2012; Marselle et al. 2015) (Table 9.4). 


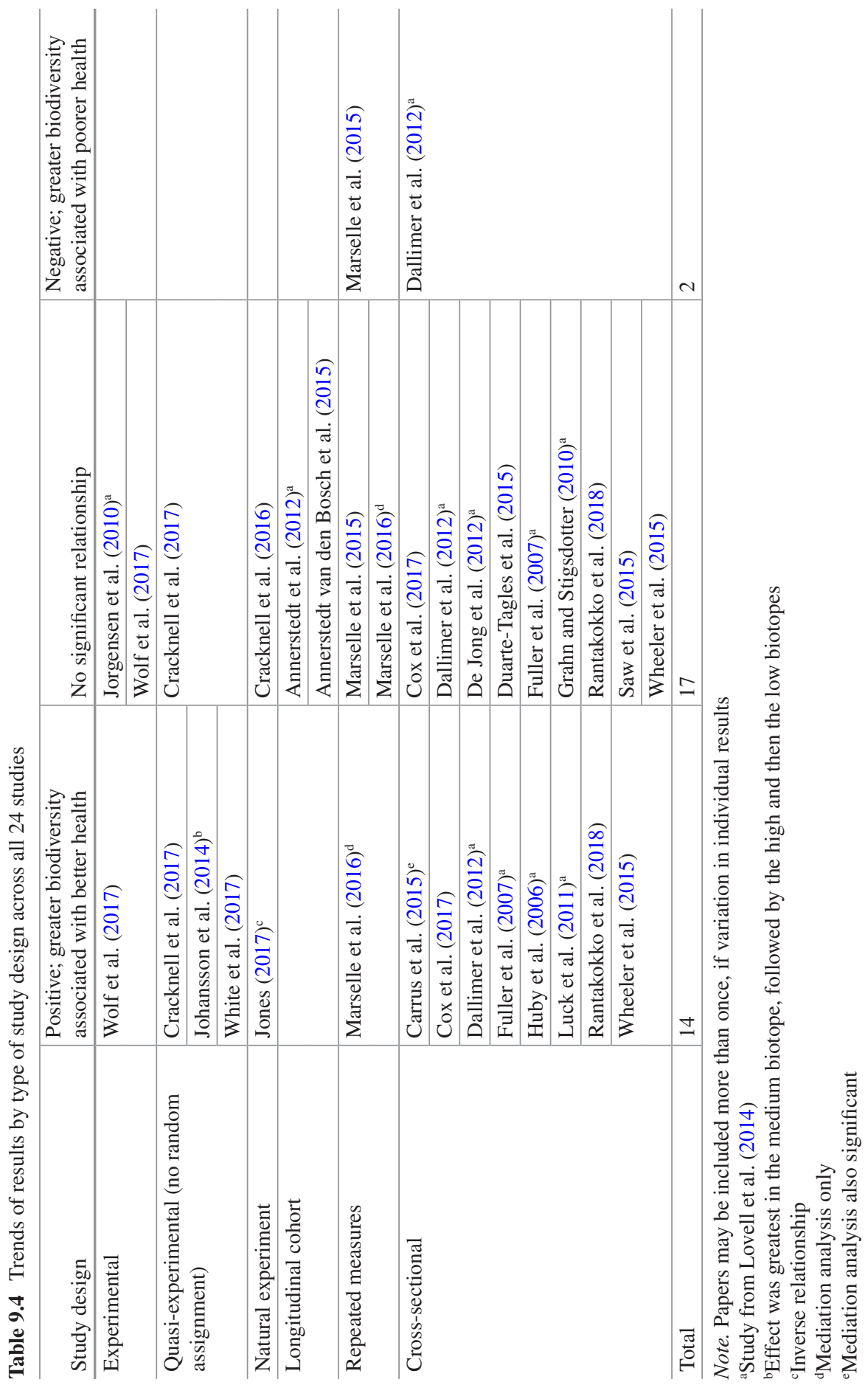




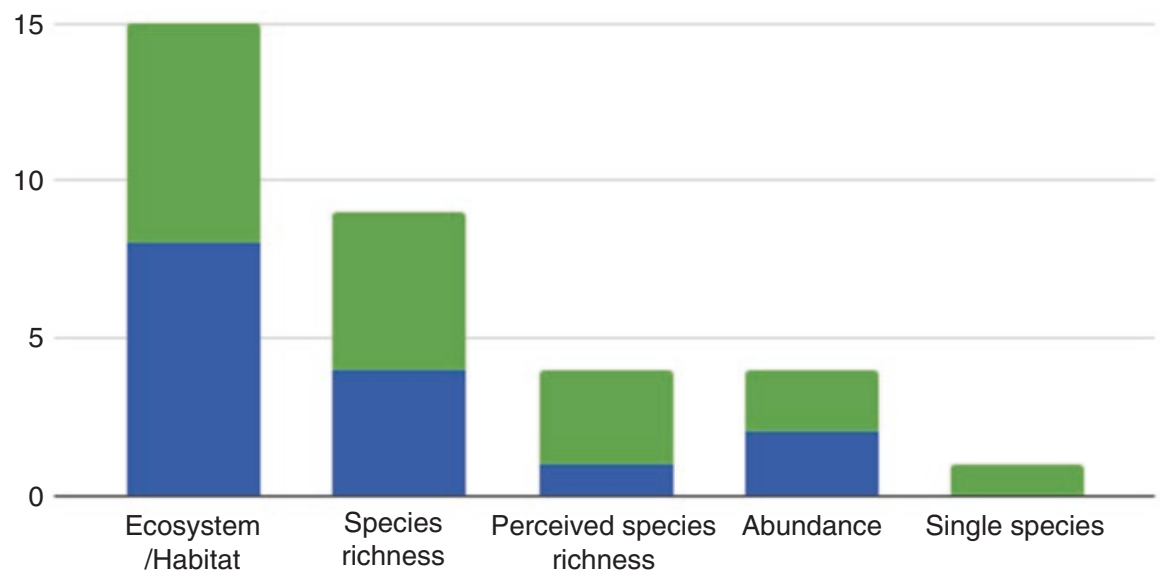

Cumulative number of studies by biodiversity level

Number of studies since Lovell et al. (2014) Number of Lovell et al. (2014) studies

Fig. 9.4 Biodiversity levels addressed by the 24 studies on the mental health and well-being effects of biodiversity. The sum may exceed $100 \%$ because studies address more than one level of biodiversity

Biodiversity levels were not equally covered by the 24 studies (see Fig. 9.4). Fifteen studies assessed biodiversity at the ecosystem/habitat level, with clear decreases to the single species level. However, the number of studies investigating biodiversity at these other levels has increased since Lovell et al. (2014).

\subsubsection{Pattern of Results}

To identify patterns in the results, we examined studies by biodiversity level and mental health and well-being outcomes (Table 9.5). We also identified the specific biodiversity variable that was measured (e.g. habitat types, birds) next to each result. The purpose was to gain insight into when biodiversity influences mental health and well-being and when it does not.

\section{Mental Health and Well-being Outcomes}

We started by looking at the results by outcome measure to determine if either outcome was more influenced by biodiversity. Nine studies investigated mental health outcomes, the majority of which were published after 2012, demonstrating a growth area for the field since Lovell et al. (2014). Mental well-being was investigated in 19 of the 24 studies. Two-thirds of the results $(65 \%)$ pertaining to the influence of 
Table 9.5 Pattern of results by biodiversity levels and mental health and well-being indicator ( $n=24$ studies)

\begin{tabular}{|c|c|c|}
\hline & \multicolumn{2}{|l|}{ Outcome variable } \\
\hline Biodiversity levels & Mental health & Mental well-being \\
\hline \multicolumn{3}{|l|}{ Ecosystems/habitats } \\
\hline & $\begin{array}{l}\text { Annerstedt van den Bosch } \\
\text { et al. (2015) } \\
\text { (o) Scania Green Score } \\
\text { 'Lush, rich in species' } \\
\text { Annerstedt et al. (2012) } \\
\text { (o) Scania Green Score } \\
\text { 'Lush, rich in species' } \\
\text { Duarte-Tagles et al. (2015) } \\
\text { (o) Margalef Diversity of } \\
\text { eco-regions } \\
\text { Rantakokko et al. (2018) } \\
\text { (o) Shannon Diversity of } \\
\text { land use }\end{array}$ & 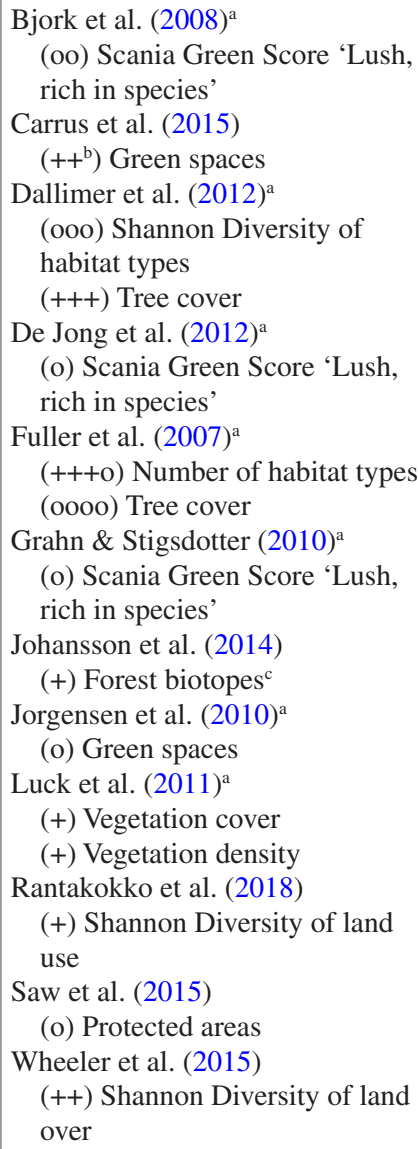 \\
\hline
\end{tabular}


Table 9.5 (continued)

\begin{tabular}{|c|c|c|}
\hline & Outcome variable & \\
\hline Biodiversity levels & Mental health & Mental well-being \\
\hline \multicolumn{3}{|l|}{ Species communities } \\
\hline Species richness & $\begin{array}{l}\text { Cox et al. (2017) } \\
\quad \text { (ooo) Morning birds } \\
\quad \text { (ooo) Afternoon birds } \\
\text { Huby et al. (2006) } \\
\quad \text { (+) Birds } \\
\text { Wolf et al. (2017) } \\
\quad \text { (+) Trees } \\
\quad \text { (+) Birds }\end{array}$ & $\begin{array}{l}\text { Cracknell et al. (2016) } \\
\text { (oo) Fish/crustaceans } \\
\text { Cracknell et al. (2017) } \\
\text { (o) Fish/crustaceans } \\
\text { Dallimer et al. (2012) } \\
\text { (+++) Birds } \\
\text { (---) Plants } \\
\text { (ooo) Butterflies } \\
\text { Fuller et al. (2007) } \\
\text { (++oo) Birds } \\
\text { (++oo) Plants } \\
\text { (oooo) Butterflies } \\
\text { Luck et al. }(2011)^{\mathrm{a}} \\
\text { (+) Birds } \\
\text { Wheeler et al. (2015) } \\
\text { (+o) Birds } \\
\text { Wolf et al. }(2017) \\
\text { (+o) Trees } \\
\text { (+o) Birds }\end{array}$ \\
\hline Perceived species richness & & $\begin{array}{l}\text { Dallimer et al. }(2012)^{\mathrm{a}} \\
(+++) \text { Birds } \\
(+++) \text { Plants/trees } \\
\text { (+++) Butterflies } \\
\text { Marselle et al. (2016) } \\
\text { (+++) Birds } \\
\text { (ooo) Plants/trees }{ }^{\mathrm{b}} \\
\text { (ooo) Butterflies }{ }^{\mathrm{b}} \\
\text { Marselle et al. }(2015) \\
\text { (-oo) Birds } \\
\text { (ooo) Plants/trees } \\
\text { (ooo) Butterflies } \\
\text { White et al. }(2017) \\
\text { (+++) Animals/plants }\end{array}$ \\
\hline $\begin{array}{l}\text { Abundance of a specific } \\
\text { taxonomic group }\end{array}$ & $\begin{array}{l}\text { Cox et al. (2017) } \\
\text { (ooo) Morning birds } \\
(+++) \text { Afternoon birds }\end{array}$ & $\begin{array}{l}\text { Cracknell et al. (2017) } \\
(+) \text { Fish/crustaceans } \\
\text { Dallimer et al. }(2012)^{\mathrm{a}} \\
(+++) \text { Birds } \\
\text { Luck et al. }(2011)^{\mathrm{a}} \\
\text { (+) Birds }\end{array}$ \\
\hline
\end{tabular}


Table 9.5 (continued)

\begin{tabular}{l|l|l}
\hline & Outcome variable & Mental well-being \\
\hline Biodiversity levels & Mental health & $\begin{array}{l}\text { Jones }(2017) \\
(+)^{\mathrm{d}} \text { Ash trees }\end{array}$ \\
\hline Single species & $\begin{array}{l}\text { Jones }(2017) \\
(+)^{\mathrm{d}} \text { Ash trees }\end{array}$ &
\end{tabular}

Note. Papers may be included more than once, if variation in individual results. Biodiversity levels are based on Botzat et al. (2016). Biodiversity variables with a slash ('/') are a combined variable where investigator did not separate out the contribution of each taxon; two taxa are analysed together. Each -, o or + symbol represents the direction of each individual result reported in the paper. $-=$ significant negative relationship; $o=$ non-significant relationship $;+=$ significant positive relationship

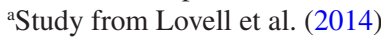

${ }^{b}$ Mediation analysis

${ }^{\mathrm{c}}$ Effect was greatest in the medium biotope, followed by the high and then the low biotopes

dinverse relationship

biodiversity on mental health were non-significant. About half of the results $(49 \%)$ showed non-significant relationships between biodiversity and mental well-being. These findings suggest that the results are equally ambiguous for both mental health and mental well-being.

\section{Ecosystems/Habitats}

Sixteen studies investigated the impact of biodiversity at the ecosystem/habitat level on mental health and well-being (Table 9.5). All 4 of the studies that assessed the influence of ecosystem/habitat biodiversity on mental health were non-significant (Annerstedt van den Bosch et al. 2015; Annerstedt et al. 2012; Duarte-Tagles et al. 2015; Rantakokko et al. 2018).

Results were mixed for the 12 studies that investigated the impact of biodiversity at the ecosystem/habitat level on mental well-being. Positive relationships were found for Shannon Diversity Index of land cover and land use, and mental wellbeing; more biodiverse ecosystems/habitats were positively associated with greater quality of life (Rantakokko et al. 2018) and good health (Wheeler et al. 2015), and negatively associated with poor health (Wheeler et al. 2015). Non-significant results for Shannon Diversity Index of habitat types were found (Dallimer et al. 2012). Greater vegetation cover and density of vegetation cover were associated with greater life satisfaction (Luck et al. 2011). Number of habitat types was associated with greater reflection and distinct identity (Fuller et al. 2007). Tree cover was positively associated with greater reflection, continuity with the past and attachment in Dallimer et al. (2012), but was non-significant in Fuller et al. (2007). A significant non-linear trend of forest biotope on positive affect was also found; intermediate biotope was rated the most positive followed by the high biotope and the low biotope (Johansson et al. 2014). Carrus et al. (2015) found biodiversity of different 
green spaces had a significant direct, and indirect, effect on general well-being. Individuals in the high biodiversity condition had greater general well-being scores than individuals in the low biodiversity condition, and perceived restorativeness mediated the relationship between biodiversity and well-being (Carrus et al. 2015). Studies assessing ecosystems/habitats by Scania Green Score 'lush, rich in species' (Björk et al. 2008; de Jong et al. 2012; Grahn and Stigsdotter 2010), protected areas (Saw et al. 2015) and green space types (Jorgensen et al. 2010) on mental wellbeing were all non-significant.

\section{Species Richness}

Ten studies examined the effect of species richness (Table 9.5). Three of these investigated the influence of species richness on mental health, with mixed results. Huby et al. (2006) found positive associations between mental health and greater bird species richness. Similarly, Wolf et al. (2017) found that participants in the high species rich conditions of trees and birds, reported less anxiety, compared to participants in the low species rich conditions. However, Cox et al. (2017) found no influence of morning and afternoon bird species richness on depression, anxiety or stress.

Across the 7 studies that measured mental well-being just over half of results (55\%) were non-significant. Specifically, there was no difference in positive affect and arousal between low and high species richness conditions of fish/crustaceans (Cracknell et al. 2016). Additionally, species richness of fish/crustaceans had no effect on happiness, when species abundance was held constant (Cracknell et al. 2017). There was also no difference in vitality scores between the high and low species richness conditions of birds and trees (Wolf et al. 2017). However, for positive affect, participants reported higher levels in the high species richness conditions of trees, and birds, compared to low species richness conditions (Wolf et al. 2017). Bird species richness was positively associated with good health (Wheeler et al. 2015). However, the negative association between bird species richness and poor health did not hold when accounting for covariates (Wheeler et al. 2015). Butterfly species richness had no significant effect (Dallimer et al. 2012; Fuller et al. 2007), and plant species richness had a negative effect, on psychological well-being (Dallimer et al. 2012). Greater species richness of birds (Dallimer et al. 2012; Fuller et al. 2007; Luck et al. 2011) and plants (Fuller et al. 2007) were both associated with greater mental well-being.

\section{Perceived Species Richness}

No study investigated the effect of perceived richness on mental health (see Table 9.5). Four studies examined the influence of perceived species richness on mental well-being. Just over half of the results (53\%) demonstrated a positive effect. 
White et al. (2017) found that greater perceived species richness of animals/plants was associated with more positive mood, arousal and recovery. Dallimer et al. (2012) found positive associations between perceived species richness of birds, butterflies and plants/trees and psychological well-being (measured as reflection, continuity with the past and attachment). Using the same perceived species richness variables, Marselle et al. $(2015,2016)$ found no associations between perceived plant/tree and butterfly species richness and emotional well-being; perceived bird species richness had no influence on positive affect and happiness but was associated with an increase in negative affect (Marselle et al. 2015). An indirect effect of perceived bird species richness on positive affect, happiness and negative affect through perceived restorativeness was also found (Marselle et al. 2016). Bird biodiversity was associated with greater perceived restorativeness, which was in turn associated with greater positive affect and happiness, and reduced negative affect.

\section{Abundance of Specific Taxonomic Groups}

Abundance was investigated in 4 studies (see Table 9.5). One study examined the impact on mental health, with mixed results. Cox et al. (2017) found that afternoon, but not morning, bird abundance was associated with less depression, anxiety and stress. The reason for this difference for mental health, according to Cox et al. (2017), is that afternoon abundance is a measure of the number of birds that people are likely to experience, as opposed to a measure of the total number of birds that are actually there. Three studies investigated the influence of the abundance of specific taxonomic groups on mental well-being, all with positive results. Bird abundance was positively associated with reflection, continuity with the past and attachment (Dallimer et al. 2012) and life satisfaction (Luck et al. 2011). Greater abundance of fish/crustaceans, viewed in photographs, was related to greater reported happiness, when species richness was held constant (Cracknell et al. 2017). This suggests that it may be the quantity of fish/crustaceans, and not the number of species per se, that influences happiness.

\section{Single Species}

One study assessed the effect of biodiversity loss by investigating the decline of a single species, the North American ash tree following infestation by the invasive emerald ash borer, on mental health and well-being (Jones 2017). The loss of ash trees, 5 years after initial infestation, was associated with an increase in depression, as well as a decrease in life satisfaction. The results suggest the negative influence that biodiversity loss could have on mental health and well-being. 


\subsection{Discussion}

This chapter identifies, summarises and synthesises research on the impact of biodiversity on mental health and mental well-being. This was done by identifying and describing the body of evidence, published since Lovell et al.'s (2014) systematic review, relating biodiversity to mental health and well-being, and by synthesising results from the studies identified by both Lovell et al. (2014) and in this chapter.

Sixteen primary research studies met our inclusion criteria. The assessment of biodiversity in these recently published studies has improved, compared to the studies reviewed in Lovell et al. (2014). Four studies in Lovell et al.'s (2014) review did not directly assess biodiversity (Barton et al. 2009; Curtin 2009; Lemieux et al. 2012; Pereira et al. 2005). The growing availability of biodiversity-focused studies meant that all 16 studies identified for our updated review considered the diversity of the environment in some way. Additionally, the recent body of literature investigates a greater variation of the biodiversity at the species community and single species levels. Further, the number of studies investigating mental health has grown since Lovell et al. (2014).

Our synthesis of the combined set of 24 studies (nine from Lovell et al. (2014) and 15 identified in this Chapter) was conducted to describe the body of literature focused on mental health and well-being as an outcome. There is some evidence to suggest that biodiverse natural environments may be associated with good mental health and well-being. Fourteen of these studies showed one or more positive relationships manifested as either better mental health or mental well-being. Positive relationships were found across all, but one, study designs. Positive relationships were most evident when assessing species abundance and mental well-being relationships. However, 17 of these studies reported one or more non-significant findings. Non-significant effects were found across all study designs, and were most evident when assessing impact of biodiversity at the ecosystem/habitat level on mental health. There was some evidence of negative relationships (in 2 of the 24 quantitative studies). Overall, the body of evidence across these 24 studies is not yet of the extent necessary to characterise the role of biodiversity in relation to mental health and/or mental well-being. Variation in the evidence may relate to the level at which biodiversity is investigated, how the biodiversity data are collected, and which taxonomic groups are explored. These raise issues for cross-study comparability.

The synthesis of results suggests that abundance of specific taxonomic groups may be an important variable. Abundance of a taxonomic group may be more noticeable by people than the number of species (Dallimer et al. 2012). As such, it may not be the number of different species (i.e. species richness) that matter, but the total number of animals, plants or birds (i.e. abundance). Indeed, Cracknell et al. (2017) found differential results between species richness and abundance on mental well-being; only abundance was related to happiness, but not species richness. Similar results were found elsewhere (Hedblom et al. 2017).

Clear gaps in the research were also found. None of the 24 studies investigated the effect of perceived species richness on mental health. Another possible area of investigation, not assessed in any of the 24 studies, is participants' perception of the abundance of a specific taxonomic group on mental health and/or mental well-being. 
Lovell et al. (2014) provided a number of recommendations for future research, which were to improve study design, and specify the type of contact and frequency of exposure to biodiversity, and test for moderating and mediating variables. Most of the recently published studies were cross-sectional; a similar observation made by Lovell et al. (2014). However, the number of robust research designs (experimental, natural experimental, longitudinal), as well as quasi-experimental and before-and-after repeated measures studies has increased, reflecting the call for improved study designs. Additionally, 2 studies sought to examine impacts of changes in biodiversity on mental health and well-being outcomes, which is an increase from Lovell et al. (2014), which had no such studies. Regarding contact with biodiversity, more than half of the recently published studies explicitly investigated direct and indirect contact, thus heeding Lovell et al.'s (2014) call to investigate how type of contact with the biodiverse environment may influence outcomes. However, no studies have yet heeded Lovell et al.'s (2014) call for investigations of frequency of exposure to biodiversity. Four of the identified 16 studies investigated moderators that qualified the biodiversity and mental health and well-being relationship. Three of the recently published studies conducted mediation analyses to determine the mechanisms through which biodiversity affects mental health and/or well-being. These few moderator and mediator studies are nevertheless an increase from those reported in Lovell et al. (2014).

\subsubsection{Concluding Observations}

In conclusion, we provide some thoughts to guide future research:

\section{Better Integration}

By its nature, the questions considered within this field of inquiry are interdisciplinary and thus by necessity require integration of natural, social and health sciences. Future research should be interdisciplinary as this will improve measurement of biodiversity, mental health and well-being.

\section{Research Design}

We encourage researchers to consider more robust designs such as before-and-after comparison studies, as well as to take advantage of natural experiment situations, and to consider development of integrative mixed method studies. Experimental studies, which test short-term effects, are particularly suited for assessing changes in momentary mental well-being. Future reviews of the influence of biodiversity and health could include a statistical meta-analysis to address the limitations from vote-counting reported here and in Lovell et al. (2014). Qualitative research designs could help identify what aspects of biodiversity people attend to, and what experiences this creates. This information could help to unravel the process by which biodiversity affects mental health and well-being.

\section{Biodiversity Assessment}

We encourage future research to use well accepted approaches for measuring biodiversity in the field or from secondary data, such as those used in the ecological 
literature. The synthesis presented here indicates that different metrics of biodiversity (e.g. species richness; abundance) could play a role and should, therefore, have their relationships with mental health and well-being assessed separately. Functional aspects of biodiversity, such as phenotypic diversity (colour of fish, height of trees) (Botzat et al. 2016) and charismatic species (Dallimer et al. 2012) could also be usefully explored. Further, studies should also measure the biodiversity that is experienced by people, as opposed to the objectively measured diversity in an environment. The bird hiding in a bush, or the nocturnal mammal, that is not seen nor heard, is unlikely to be experienced by humans, and unlikely to influence mental health or well-being (Bell et al. 2014; Cox et al. 2017). Assessments of the biodiversity that people perceive or experience can be captured with Global Positioning System (GPS) trackers, eye-tracking technology and mobile electroencephalography (EEG) devices. We also recognise that one's perception of biodiversity is important for health and well-being. The synthesis presented here demonstrated that perceived species richness is associated with mental well-being. Future studies could investigate perceived species richness-mental health relationships. Further, whilst not investigated in any of the studies reviewed here, perceived biodiversity could also be investigated to assess whether it mediates the effect of objectively measured biodiversity on mental health and/or well-being. See de Vries and Snep Chap. 8, this volume, for further discussion on biodiversity measurement considerations.

\section{Mental Health and Well-being Assessment}

To facilitate cross study comparison, we encourage future research to use validated scales of mental health and well-being that have been used previously in psychology and health. ${ }^{2}$ As such, researchers may wish to consider the reliability of using a mental health or well-being measure for understanding the biodiversity-health relationship. When developing new measures, theoretically grounded outcome measures are essential.

\section{Theory}

Future studies should articulate the theoretical framework(s) they are using to hypothesise about biodiversity-health relationships (see also Marselle Chap. 7, this volume). Researchers should use theory to drive the selection of outcome measures and identify mediators, moderators and confounders. To our knowledge, no study has investigated the effect of biodiversity on attention restoration, and more studies could investigate stress as an outcome measure; both of which explicitly test theories of restorative environments. Additionally, theories on the relationship of natural environments on health, such as Attention Restoration Theory could be developed further, e.g. by differentiating general effects of natural environments, and specific aspects of biodiversity, on health aspects.

\section{Mechanisms}

Future studies should continue to investigate the mediators of biodiversity and mental health and well-being using the pathways identified in nature-health frameworks (Hartig et al. 2014; Markevych et al. 2017).

\footnotetext{
${ }^{2}$ Researchers may wish to see Linton et al. (2016) for a list of such measures.
} 


\section{Moderators}

Future studies should continue to investigate personal and contextual factors as moderators (Markevych et al. 2017) of biodiversity-mental health and well-being relationships.

\section{Dose-Response Relationships}

None of the studies examined dose-response relationships of biodiversity on mental health and well-being. At present, we do not know how much biodiversity is required for an effect, how long before effects take place, or how long they last. For example, future studies could usefully investigate the amount of time spent in the biodiverse environment required for a change in mental health or well-being.

Acknowledgements Thanks are due to Professor Zoe Davies and Professor Aletta Bonn for their comments on an earlier draft of this manuscript, the three peer reviewers, and to Popay et al. (2006) for permission to use the ESRC-funded Narrative Synthesis guidance. Dr. Martens' involvement was supported through funding from the Federal Agency for Nature Conservation, Germany. Dr. Irvine's involvement was supported through funding from Rural \& Environment Science \& Analytical Services Division of the Scottish Government. Dr. Dallimer's involvement was supported by the UK government's Natural Environment Research Council (NERC) grant number NE/R002681/1.

\section{Appendix: Search Terms Used in Web of Science}

\begin{tabular}{|c|c|c|}
\hline & Search terms used & $\begin{array}{l}\text { Number of } \\
\text { references } \\
\text { found }\end{array}$ \\
\hline$\# 01$ & $\begin{array}{l}\text { Biodiversity OR ‘species richness' OR ‘protected area*' AND ‘mental } \\
\text { health' OR 'mental well-being' OR ‘social cohesion' OR ‘social well-being' } \\
\text { or 'physical activity’ TS = (biodiversity OR ‘species richness' or 'protected } \\
\text { area*’) AND TS = ('mental health‘ OR ‘mental well-being' OR ‘social } \\
\text { cohesion' OR ‘social well-being' or 'physical activity') AND DOCUMENT } \\
\text { TYPES: (Article). Timespan: 2013-2017. Indexes: SCI-EXPANDED, SSCI, } \\
\text { A\&HCI, ESCI. }\end{array}$ & 79 \\
\hline$\# 02$ & biodiversity AND 'mental health' & 23 \\
\hline$\# 03$ & biodiversity AND 'mental well-being' & 3 \\
\hline$\# 04$ & 'species richness' AND 'mental health' & 5 \\
\hline$\# 05$ & 'species richness' AND 'mental well-being' & 1 \\
\hline \#06 & 'protected area' AND 'mental health' & 1 \\
\hline$\# 07$ & 'protected area' AND 'mental well-being' & 0 \\
\hline$\# 08$ & biodiversity AND 'physical activity' & 39 \\
\hline$\# 09$ & 'species richness' AND 'physical activity' & 6 \\
\hline$\# 10$ & 'protected area' AND 'physical activity' & 3 \\
\hline$\# 11$ & 'protected area' AND ‘social cohesion' & 4 \\
\hline$\# 12$ & 'protected area' AND 'social well-being' & 2 \\
\hline$\# 13$ & biodiversity AND 'social cohesion’ & 16 \\
\hline$\# 14$ & 'species richness' AND 'social cohesion' & 0 \\
\hline$\# 15$ & 'species richness' AND 'social well-being' & 0 \\
\hline \multirow[t]{2}{*}{$\# 16$} & biodiversity AND 'social well-being' & 4 \\
\hline & Total references & 189 \\
\hline
\end{tabular}




\section{References}

Annerstedt van den Bosch MA, Östergren P, Grahn P, Skärbäck E, Währborg P (2015) Moving to serene nature may prevent poor mental health-results from a swedish longitudinal cohort study. Int J Environ Res Public Health 12:7974-7989

Annerstedt M, Östergren P, Björk J, Grahn P, Skärbäck E, Währborg P (2012) Green qualities in the neighbourhood and mental health - results from a longitudinal cohort study in Southern Sweden. BMC Public Health 12:337

Barton J, Hine R, Pretty J (2009) The health benefits of walking in green spaces of high natural and heritage value. J Integr Environ Sci 6:261-278

Bell R, Irvine K, Wilson C, Warber S (2014) Dark nature: exploring potential benefits of nocturnal nature-based interaction for human and environmental health. Eur J Ecopsychol 5:1-15

Björk J, Albin M, Grahn P, Jacobsson H, Ardö J, Wadbro J, Östergren P, Skärbäck E (2008) Recreational values of the natural environment in relation to neighbourhood satisfaction, physical activity, obesity and wellbeing. J Epidemiol Community Health 62(4):e2. https://doi. org/10.1136/jech.2007.062414

Botzat A, Fischer LK, Kowarik I (2016) Unexploited opportunities in understanding liveable and biodiverse cities. A review on urban biodiversity perception and valuation. Glob Environ Chang 39:220-233

Bowler DE, Buyung-Ali L, Knight T, Pullin AS (2010) A systematic review of evidence for the added benefits to health of exposure to natural environments. BMC Public Health 10:456. https://doi.org/10.1186/1471-2458-10-456

Carrus G, Scopelliti M, Lafortezza R, Colangelo G, Ferrini F, Salbitano F, Agrimi M, Portoghesi L, Semenzato P, Sanesi G (2015) Go greener, feel better? The positive effects of biodiversity on the well-being of individuals visiting urban and peri-urban green areas. Landsc Urban Plan $134: 221-228$

Convention on Biological Diversity (2017a) Recommendation adopted by the subsidiary body on scientific, technical and technological advice. XXI/3. Health and biodiversity. Available: https://www.cbd.int/doc/recommendations/sbstta-21/sbstta-21-rec-03-en.pdf. Accessed 17 May 2018

Convention on Biological Diversity (2017b) Workshop on Biodiversity and Health for the European Region. Available via: https://www.cbd.int/health/european/default.shtml. Accessed 17 May 2018

Cǒté IM, Curtis PS, Rothstein HR, Steward GB (2013) Gathering data: searching literature and selection criteria. In: Koricheva J, Gurevitch J, Mengersen K (eds) Handbook of meta-analysis in ecology and evolution. Princeton University Press, Princeton, p 37

Cox DTC, Shanahan DF, Hudson HL, Plummer KE, Sirwardena GM, Fuller RA, Anderson K, Hancock S, Gaston KJ (2017) Doses of neighborhood nature: the benefits for mental health of living with nature. Bioscience 67:147-155. https://doi.org/10.1093/biosci/biw173

Cracknell D, White MP, Pahl S, Nichols WJ, Depledge MH (2016) Marine biota and psychological well-being: a preliminary examination of dose-response effects in an aquarium setting. Environ Behav 48(10):1242-1269. https://doi.org/10.1177/0013916515597512

Cracknell D, White MP, Pahl S Depledge MH (2017) A preliminary investigation into the restorative potential of public aquaria exhibits: a UK student-based study. Landsc Res 42(1):18-32. https://doi.org/10.1080/01426397.2016.1243236

Curtin S (2009) Wildlife tourism: the intangible, psychological benefits of human-wildlife encounters. Curr Issue Tour 12(451):474

Dadvand P, Nieuwenhuijsen MJ, Esnaola M et al (2015) Green spaces and cognitive development in primary schoolchildren. PNAS 112(26):7937-7942

Dallimer M, Irvine KN, Skinner AMJ et al (2012) Biodiversity and the feel-good factor: understand associations between self-reports human well-being and species richness. Bioscience 62(1):47-55 
de Jong K, Albin M, Starback E et al (2012) Perceived green qualities were associated with neighborhood satisfaction, physical activity, and general health: results from a cross-sectional study in suburban and rural Scania, southern Sweden. Health Place 18:1374-1380

Diener E, Emmons R, Larsen R, Griffin S (1985) The satisfaction with life scale. J Pers Assess 49(1):71-75

Duarte-Tagles H, Salinas-Rodriguez A, Idrovo AJ et al (2015) Biodiversity and depressive symptoms in Mexican adults: exploration of beneficial environmental effects. Biomedica 35:46-57. https://doi.org/10.7705/biomedica.v35i0.2433

EKLIPSE (2017) Types and components of natural or man-made urban and suburban green and blue spaces affecting human mental health and mental well-being. Available via: http://www. eklipse-mechanism.eu/documents/32503/0/Final_DoW_Health_08092017.pdf/d5e269a2da6b-4809-9458-fd9747ca383c. Accessed 15 Jan 2018

Foo CH (2016) Linking forest naturalness and human wellbeing-a study on public's experiential connection to remnant forests within a highly urbanized region in Malaysia. Urban For Urban Green 16:13-24

Frumkin H (2001) Beyond toxicity: human health and the natural environment. Am J Prev Med 20(3):234-240

Fuller RA, Irvine KN, Devine-Wright P et al (2007) Psychological benefits of greenspace increase with biodiversity. Biol Lett 3:390-394

Grahn P, Stigsdotter UK (2010) The relation between perceived sensory dimensions or urban green space and stress restoration. Landsc Urban Plan 94:264-275

Groenewegen PP, van den Berg AE, Maas J et al (2012) Is a green residential environment better for health? If so, why? Ann Assoc Am Geogr 102(5):996-1003. https://doi.org/10.1080/0004 5608.2012.674899

Hartig T, Evans GW, Jamner LD et al (2003) Tracking restoration in natural and urban field settings. J Environ Psychol 23(2):109-123

Hartig T, Mitchell R, de Vries S Frumkin H (2014) Nature and health. Annu Rev Public Health 35:207-228. https://doi.org/10.1146/annurev-publhealth-032013-182443

Hedblom M, Knez I, Gunnarsson B (2017) Bird diversity improves the well-being of city residents. In: Murgui E, Hedblom M (eds) Ecology and conservation of birds in urban environments. Springer, Cham, pp 287-306

Horwitz P, Kretsch C (2015) Contribution of biodiversity and green spaces to mental and physical fitness, and cultural dimensions of health. In: World Health Organisation, Secretariat of the Convention on Biological Diversity (eds) Connecting global priorities: biodiversity and human health. A state of the knowledge review. World Health Organization, Geneva, p 200

Hough RL (2014) Biodiversity and human health: evidence for causality? Biodivers Conserv 23:267-288

Huby M, Cinderby S, Crowe AM et al (2006) The association of natural, social and economic factors with bird species richness in rural England. J Agric Econ 57(2):295-312

Huynen M, Martens P, de Groot RS (2004) Linkages between biodiversity loss and human health: a global indicator analysis. Int J Environ Health Res 14:13-30

Irvine KN, Warber SL (2002) Greening healthcare: practicing as if the natural environment really mattered. Altern Ther Health Med 8(5):76-83

Johansson M, Gyllin M, Witzell J, Küller M (2014) Does biological quality matter? Direct and reflected appraisal of biodiversity in temperate deciduous broad-leaf forest. Urban For Urban Green 13:28-37

Jones B (2017) Invasive species impacts on human well-being using the life satisfaction index. Ecol Econ 134(250):257

Jorgensen A, Wilson E, van den Berg A (2010) Evaluating stress relief in urban green and open spaces: does perceived naturalness make a difference?

Kaplan S (1995) The restorative benefits of nature: toward an integrative framework. J Environ Psychol 15(3):169-182 
Kaplan R, Kaplan S (1989) The experience of nature: a psychological perspective. Cambridge University Press, Cambridge

Kellert SR, Wilson EO (eds) (1993) The Biophilia hypothesis. Island Press, Washington, DC

Keniger LE, Gaston KJ, Irvine KN, Fuller RA (2013) What are the benefits of interacting with nature? Int J Environ Res Public Health 10:913. https://doi.org/10.3390/ijerph10030913

Koricheva J, Gurevitch J, Mengersen K (eds) (2013) Handbook of meta-analysis in ecology and evolution. Princeton University Press, Princeton

Korpela KM, Stengård E, Jussila P (2016) Nature walks as part of a therapeutic intervention for depression. Ecopsychology 8:8-15. https://doi.org/10.1089/eco.2015.0070

Lemieux CJ, Eagles PF, Slocombe DS et al (2012) Human health and wellbeing motivations and benefits associated with protected area experiences: an opportunity for transforming policy and management in Canada. Parks 18:71-86

Linton M, Dieppe P, Medina-Lara A (2016) Review of 99 self-report measures for assessing wellbeing in adults: exploring dimensions of well-being and developments over time. BMJ Open 6(7). https://doi.org/10.1136/bmjopen-2015-010641

Lovell R, Wheeler BW, Higgins SL et al (2014) A systematic review of the health and wellbeing benefits of biodiverse environments. J Toxicol Environ Health B Crit Rev 17(1):1-20. https:// doi.org/10.1080/10937404.2013.856361

Luck GW, Davidson P, Boxall D, Smallbone L (2011) Relations between urban bird and plant communities and human well-being and connection to nature. Conserv Biol 25:816-826

Markevych I, Schoierer J, Hartig T et al (2017) Exploring pathways linking greenspace to health: theoretical and methodological guidance. Environ Res 158:301-317. https://doi.org/10.1016/j. envres.2017.06.028

Marselle MR, Irvine KN, Lorenzo-Arribas A, Warber SL (2015) Moving beyond green: exploring the relationship of environment type and indicators of perceived environmental quality on emotional well-being following group walks. Int J Environ Res Public Health 12(1):106. https:// doi.org/10.3390/ijerph120100106

Marselle MR, Irvine KN, Lorenzo-Arribas A, Warber SL (2016) Does perceived restorativeness mediate the effects of perceived biodiversity and perceived naturalness on emotional wellbeing following group walks in nature? J Environ Psychol 46:217-232

Pereira E, Queiroz C, Pereira HM, Vicente L (2005) Ecosystem services and human well-being: a participatory study in a mountain community in Portugal. Ecol Soc 10(2):41-64

Popay J, Roberts H, Sowden A et al (eds) (2006) Guidance on the conduct of narrative synthesis in systematic reviews. ESRC Methods Programme, Lancaster

Poudyal NC, Hodges DG, Bowker JM, Cordell HK (2009) Evaluating natural resource amenities in a human life expectancy production function. Forest Policy Econ 11:253-259

Rantakokko M, Keskinen KE, Kokko K, Portegijs E (2018) Nature diversity and well-being in old age. Aging Clin Exp Res 30(5):527-532. https://doi.org/10.1007/s40520-017-0797-5

Saw LE, Lim FKS, Carrasco LR (2015) The relationship between natural park usage and happiness does not hold in a tropical city-state. PLoS One 10(7):e0133781. https://doi.org/10.1371/ journal.pone. 0133781

Sieswerda LE, Soskolne CL, Newman SC et al (2001) Toward measuring the impact of ecological disintegrity on human health. Epidemiology 12:28-32

Thompson Coon J, Boddy K, Stein K et al (2011) Does participating in physical activity in outdoor natural environments have a greater effect on physical and mental wellbeing than physical activity indoors? A systematic review. Environ Sci Technol 45(5):1761-1772. https://doi. org/10.1021/es102947t

Tilt J, Unfried T, Roca B (2007) Using objective and subjective measures of neighborhood greenness and accessible destinations for understanding walking trips and BMI in Seattle, Washington. Am J Health Promot 21:371-379

Triguero-Mas M, Dadvand P, Cirach M et al (2015) Natural outdoor environments and mental and physical health: relationships and mechanisms. Environ Int 77(35):41 
Ulrich R (1983) Aesthetic and affective response to natural environment. In: Altman I, Wohlwill $\mathrm{J}$ (eds) Human behavior and the natural environment. Plenum Press, New York, pp 85-125

Ulrich R, Simons R, Losito B et al (1991) Stress recovery during exposure to natural and urban environments. J Environ Psychol 11(3):201-230

United Nations (1992) Convention on biological diversity. Available via: https://www.cbd.int/doc/ legal/cbd-en.pdf. Accessed 17 May 2018

WBGU - German Advisory Council on Global Change (2016) Humanity on the move: unlocking the transformative power of cities. WBGU, Berlin

Wheeler BW, Lovell R, Higgins SL et al (2015) Beyond greenspace: an ecological study of population general health and indicators of natural environment type and quality. Int J Health Geogr 14(1):17. https://doi.org/10.1186/s12942-015-0009-5

White MP, Weeks A, Hooper T et al (2017) Marine wildlife as an important component of coastal visits: the role of perceived biodiversity and species behaviour. Mar Policy 78(80):89

Whitmee S, Haines A, Beyrer C et al (2015) Safeguarding human health in the Anthropocene epoch: report of The Rockefeller Foundation-Lancet Commission on planetary health. Lancet 386:1973-2018. https://doi.org/10.1016/S0140-6736(15)60901-1

Wolf LJ, zu Ermgassen S, Balmford A et al (2017) Is variety the spice of life? An experimental investigation into the effects of species richness on self-reported mental well-being. PloS ONE 12(1):e0170225. https://doi.org/10.1371/journal.pone.0170225

World Health Organisation \& Secretariat of the Convention on Biological Diversity (2015) Connecting global priorities: biodiversity and human health. A state of the knowledge review. Available via: http://www.who.int/globalchange/publications/biodiversity-human-health/en/. Accessed 17 May 2017

World Health Organization (1946) Preamble to the Constitution of the World Health Organization as adopted by the International Health Conference, New York, 19 June - 22 July 1946; signed on 22 July 1946 by the representatives of 61 States (Official Records of the World Health Organization, no. 2, p. 100) and entered into force on 7 April 1948. The definition has not been amended since 1948. Available via: http://www.who.int/suggestions/faq/en/. Accessed 17 May 2018

World Health Organization (2016) Mental health: strengthening our response. Fact Sheet. Available via: http://www.who.int/mediacentre/factsheets/fs220/en/. Accessed 17 May 2018

Open Access This chapter is licensed under the terms of the Creative Commons Attribution 4.0 International License (http://creativecommons.org/licenses/by/4.0/), which permits use, sharing, adaptation, distribution and reproduction in any medium or format, as long as you give appropriate credit to the original author(s) and the source, provide a link to the Creative Commons license and indicate if changes were made.

The images or other third party material in this chapter are included in the chapter's Creative Commons license, unless indicated otherwise in a credit line to the material. If material is not included in the chapter's Creative Commons license and your intended use is not permitted by statutory regulation or exceeds the permitted use, you will need to obtain permission directly from the copyright holder.

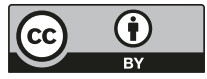

